\title{
User Manuals for the Delaware River Basin Water Availability Tool for Environmental Resources (DRB-WATER) and Associated WATER Application Utilities
}

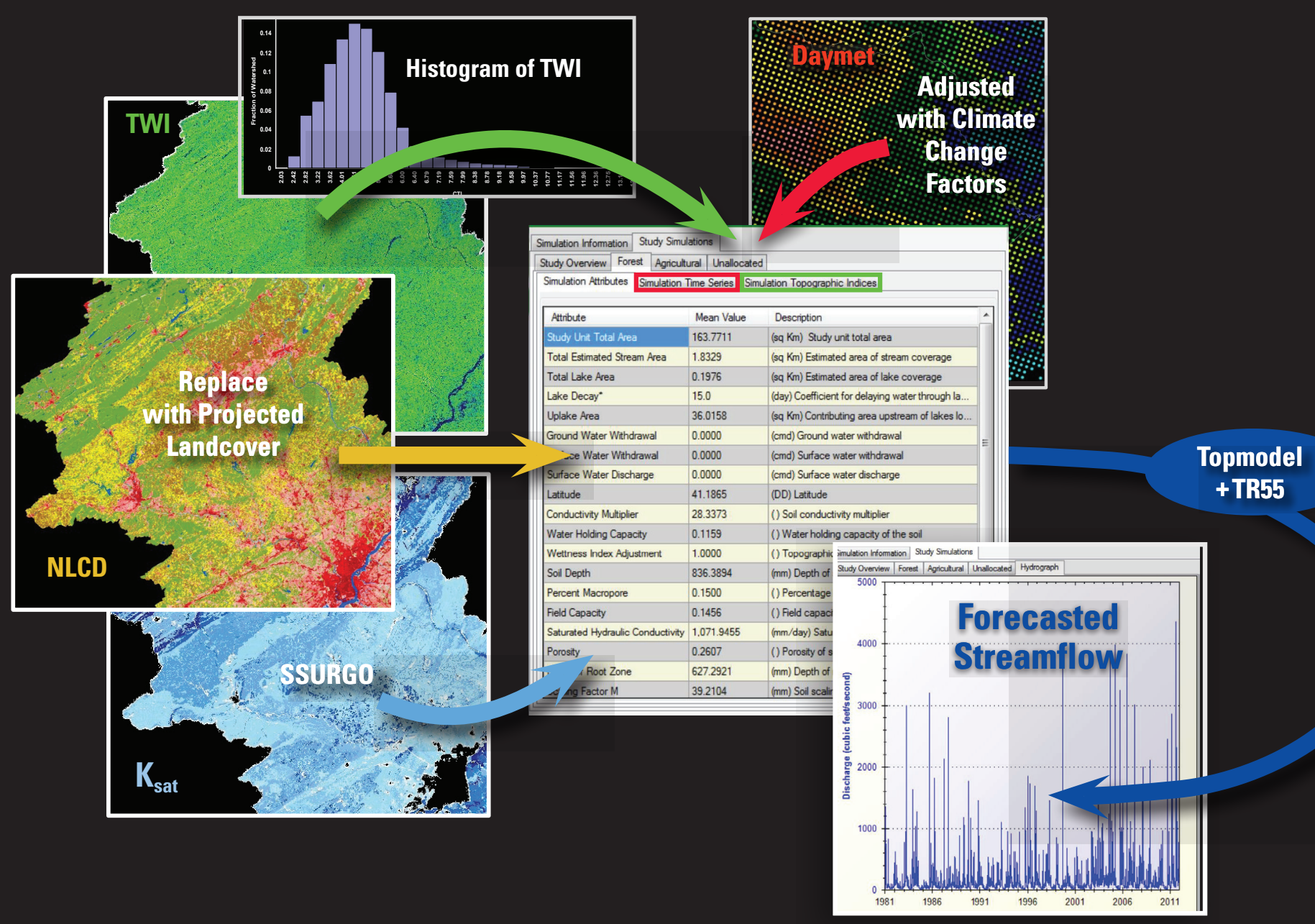

Open File Report 2015-1196

U.S. Department of the Interior U.S. Geological Survey 



\section{User Manuals for the Delaware River Basin Water Availability Tool for Environmental Resources (DRB-WATER) and Associated WATER Application Utilities}

By Tanja N. Williamson and Jeremiah G. Lant

Open File Report 2015-1196 


\title{
U.S. Department of the Interior SALLY JEWELL, Secretary
}

\section{U.S. Geological Survey \\ Suzette M. Kimball, Acting Director}

\author{
U.S. Geological Survey, Reston, Virginia: 2015
}

For more information on the USGS - the Federal source for science about the Earth, its natural and living resources, natural hazards, and the environment—visit http://www.usgs.gov or call 1-888-ASK-USGS.

For an overview of USGS information products, including maps, imagery, and publications, visit http://www.usgs.gov/pubprod/.

Any use of trade, firm, or product names is for descriptive purposes only and does not imply endorsement by the U.S. Government.

Although this information product, for the most part, is in the public domain, it also may contain copyrighted materials as noted in the text. Permission to reproduce copyrighted items must be secured from the copyright owner.

Suggested citation:

Williamson, T.N., and Lant, J.G., 2015, User manuals for the Delaware River Basin Water Availability Tool for Environmental Resources (DRB-WATER) and associated WATER application utilities: U.S. Geological Survey Open-File Report 2015-1196, 32 p., http://dx.doi.org/10.3133/ofr20151196.

ISSN 2331-1258 (online) 


\section{Contents}

Abstract

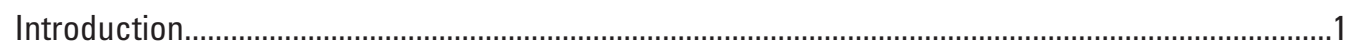

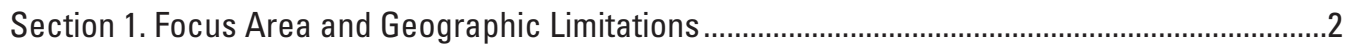

Data Sources Provided with WATER and WATER Application Utilities....................................2

Uncertainty in Simulations and Relation to Scenario Investigation........................................6

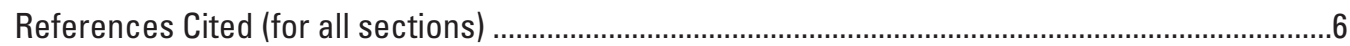

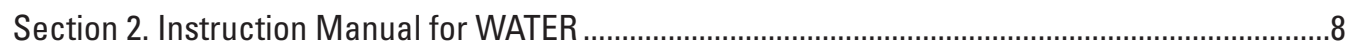

Using the Water Availability Tool for Environmental Resources (WATER)................................8

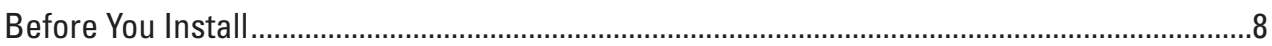

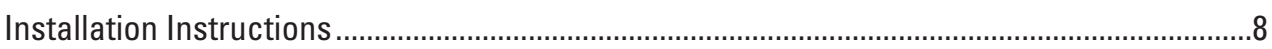

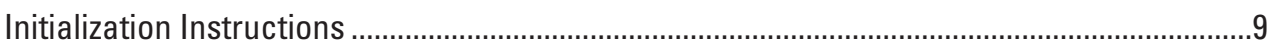

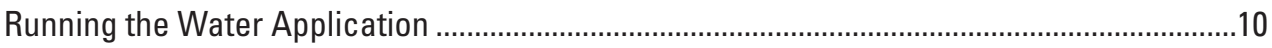

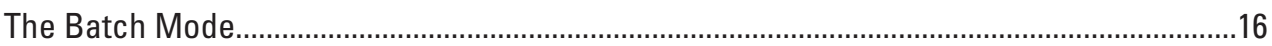

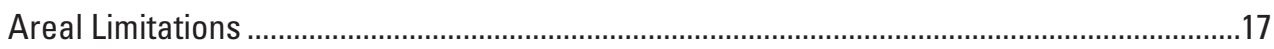

Time Period Included in Simulations ..................................................................................... 17

General Circulation Model Simulations .....................................................................................17

Land-Cover Projections ........................................................................................................... 17

Section 3. Instruction Manual for WATER Application Utilities—waterapputils version 1.0.0.......18

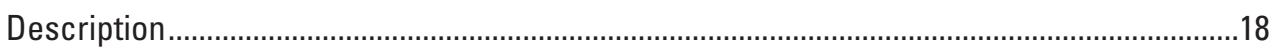

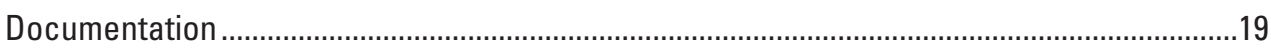

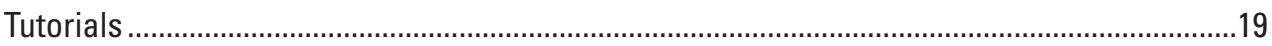

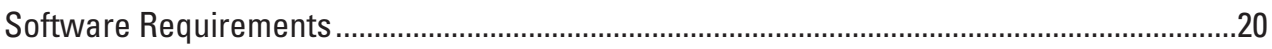

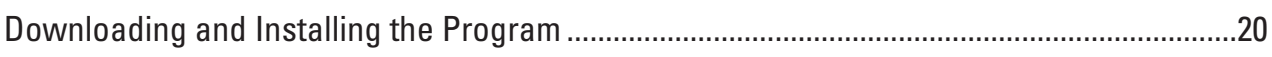

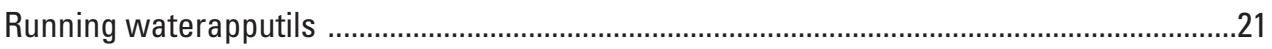

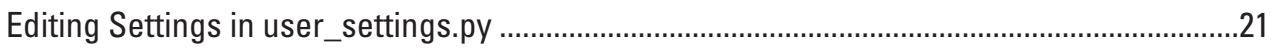

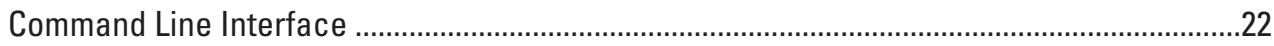

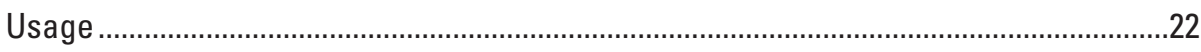

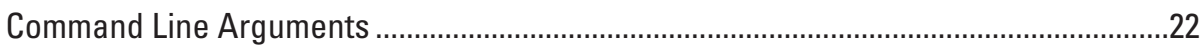

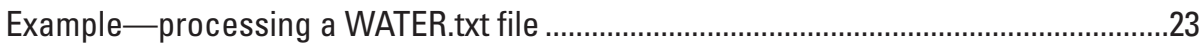

Example_-running water use using the settings in user_settings.py ..............................23

Example-running water use by supplying a path to a simulations directory instead of specifying the simulations directory in user_settings.py ...................23

Run Sample Datasets Shell Script with run_sample_datasets.sh ...........................................24

Usage — shell script to test waterapputils......................................................................24

Command-Line Arguments for the Shell Script run_sample_datasets.sh ......................24

Example - apply water use to delineated and batch simulations ...................................25

Applying Water Use or General Circulation Model Deltas to Many WATER Simulations Using run_simulations.sh...............................................................................................25

Usage - shell script for applying water use or GCM deltas to WATER simulations ......25

Command-Line Arguments for the Shell Script run_simulations.sh ................................25

Example - apply water use to many WATER simulations .................................................25 


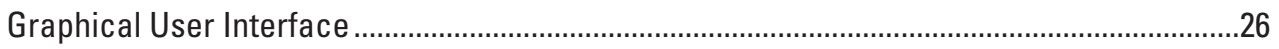

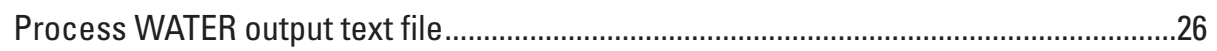

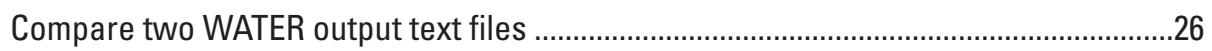

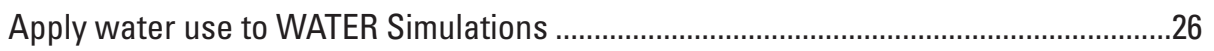

Number of simulation(s) - a user selects the number of WATER simulations.......26

Type of simulation(s) —a user selects the type of WATER simulation ....................27

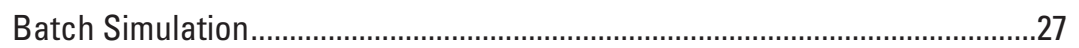

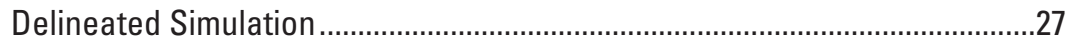

Simulation information - a user selects the WATER simulation of interest for application of water use ........................................................................27

Water-use information-a user selects seasonal water-use data files and associated information ............................................................28

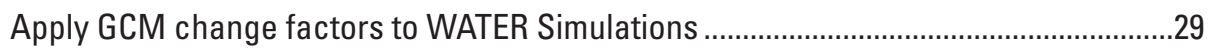

Number of simulation(s) - a user selects the number of WATER simulations......29

Type of simulation(s) - a user selects the type of WATER simulation ....................29

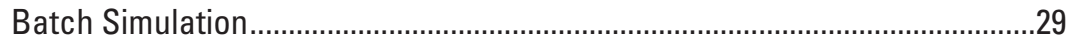

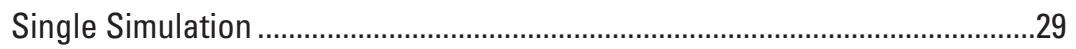

Simulation information-a user selects the WATER simulation of interest to apply GCM deltas .........................................................................30

General circulation model change factor information — a user selects three GCM delta files and associated information .................................................30

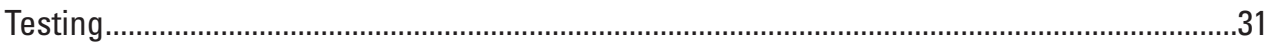

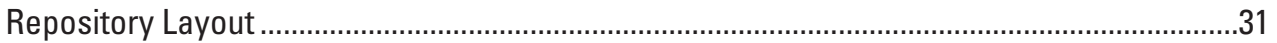

\section{Figures}

1. Map showing the Delaware River Basin, including parts of Delaware, New Jersey, New York, and Pennsylvania, as well as a small part of Maryland..

2. Map showing parts of Delaware River system where caution should be used because of stream regulation and tidal influences..................................................

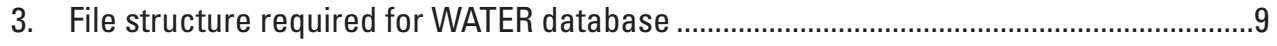

4. Installation warning for installing program...................................................................

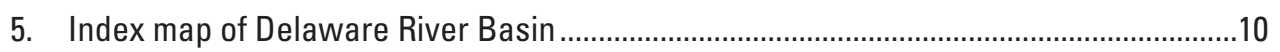

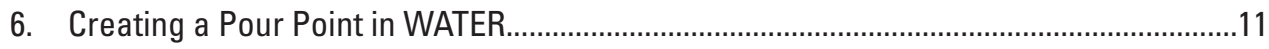

7. Dialogue box for naming simulation ...........................................................................

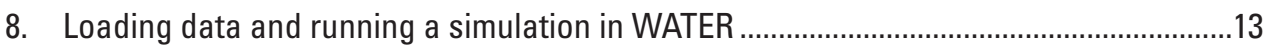

9. Spatially averaged basin characteristics for the forested part of a basin .......................14

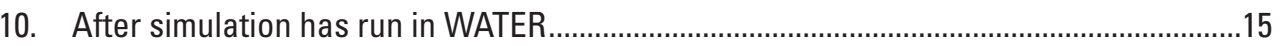

11. File structure after simulation has been run .........................................................15

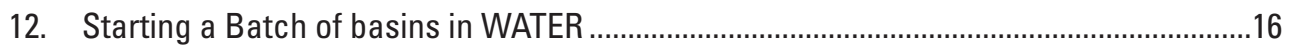

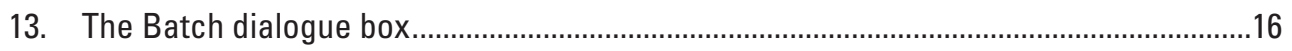

14. Sample hydrograph produced after processing and analyzing WATER output files using the graphical user interface .......................................................................

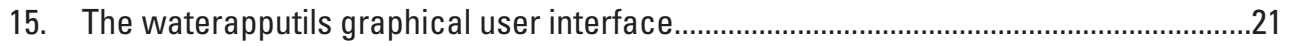




\section{Tables}

1. Data sources and citations for the Delaware River Basin Water Availability

Tool for Environmental Resources ...........................................................................5

2. General circulation models provided as part of the Water Availability Tool for Environmental Resources database.......................................................................

3. Representative concentration pathways (RCPs; summarized from van Vuuren and others, 2011)—data are provided for RCPs 4.5 and $8.5 \ldots \ldots \ldots \ldots \ldots \ldots \ldots \ldots \ldots . . .5$

4. Water-use categories and geospatial data type provided from 2010 National Water Census Inventory

\section{Conversion Factors}

International System of Units to Inch/Pound

\begin{tabular}{lcl}
\hline \multicolumn{1}{c}{ Multiply } & By & \multicolumn{1}{c}{ To obtain } \\
\hline meter $(\mathrm{m})$ & Length & foot $(\mathrm{ft})$ \\
meter $(\mathrm{m})$ & 3.281 & yard $(\mathrm{yd})$ \\
\hline kilometer $(\mathrm{km})$ & 1.094 & mile $(\mathrm{mi})$ \\
\hline \multicolumn{3}{c}{ Area } \\
\hline square kilometer $\left(\mathrm{km}^{2}\right)$ & 0.6214 & acre \\
square kilometer $\left(\mathrm{km}^{2}\right)$ & 247.1 & square mile $\left(\mathrm{mi}^{2}\right)$ \\
\hline & 0.3861 & British thermal unit per hour per \\
\hline watt per square meter $\left(\mathrm{W} / \mathrm{m}^{2}\right)$ & Radiative forcing & square foot \\
\hline
\end{tabular}

\section{Datum}

Vertical coordinate information is referenced to the North American Vertical Datum of 1988 (NAVD 88).

Horizontal coordinate information is referenced to the North American Datum of 1983 (NAD 83).

Elevation, as used in this report, refers to distance above the vertical datum. 


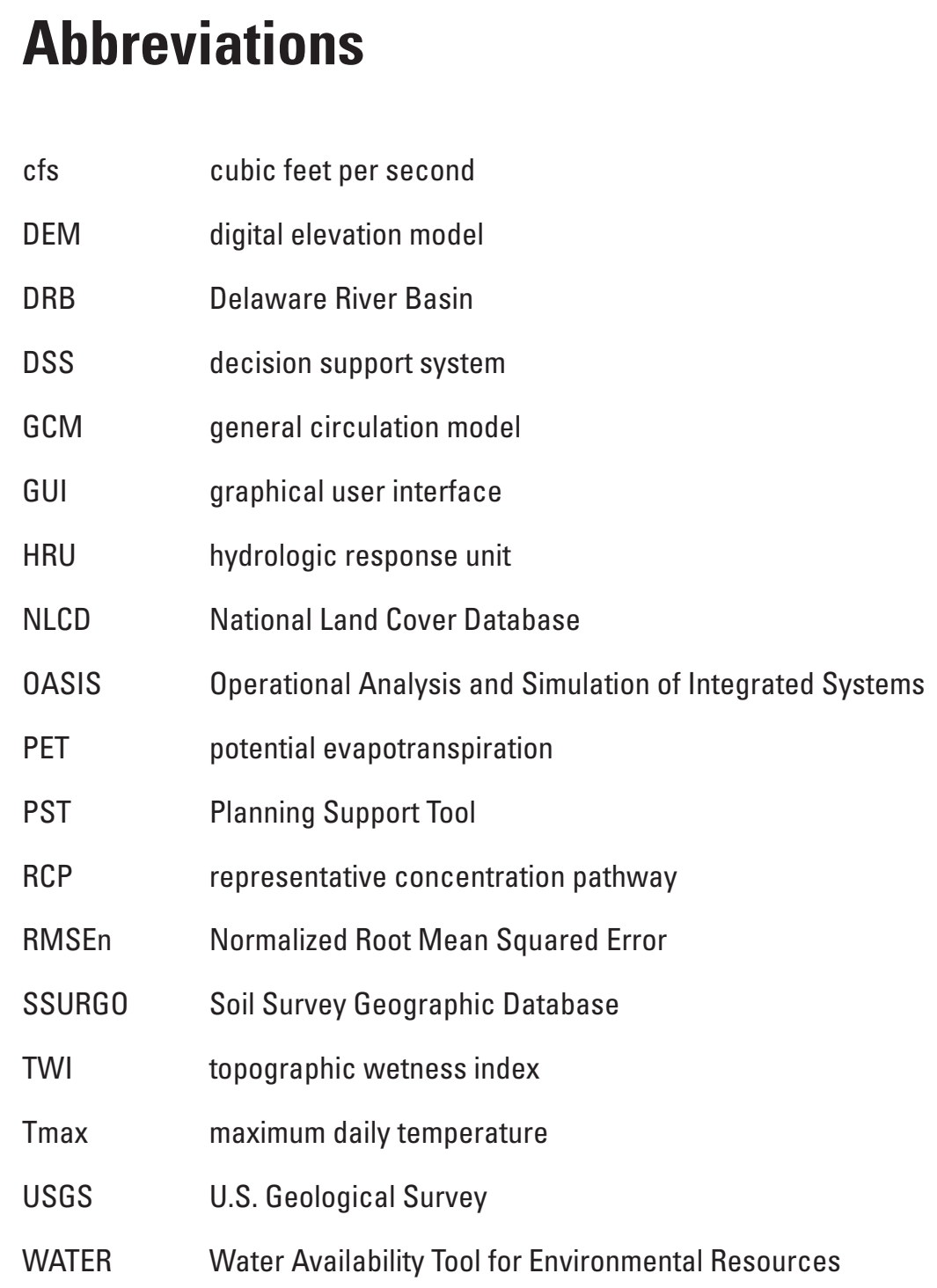




\title{
User Manuals for the Delaware River Basin Water Availability Tool for Environmental Resources (DRB-WATER) and Associated WATER Application Utilities
}

\author{
By Tanja N. Williamson and Jeremiah G. Lant
}

\section{Abstract}

The Water Availability Tool for Environmental Resources (WATER) is a decision support system (DSS) for the nontidal part of the Delaware River Basin (DRB) that provides a consistent and objective method of simulating streamflow under historical, forecasted, and managed conditions. WATER integrates geospatial sampling of landscape characteristics, including topographic and soil properties, with a regionally calibrated hillslope-hydrology model, an impervious-surface model, and hydroclimatic models that have been parameterized using three hydrologic response units - forested, agricultural, and developed land cover. It is this integration that enables the regional hydrologic-modeling approach used in WATER without requiring site-specific optimization or those stationary conditions inferred when using a statistical model. The DSS provides a "historical" database, ideal for simulating streamflow for 2001-11, in addition to land-cover forecasts that focus on 2030 and 2060. The WATER Application Utilities are provided with the DSS and apply change factors for precipitation, temperature, and potential evapotranspiration to a 1981-2011 climatic record provided with the DSS. These change factors were derived from a suite of general circulation models (GCMs) and representative concentration pathway (RCP) emission scenarios. These change factors are based on 25-year monthly averages (normals) that are centered on 2030 and 2060. The WATER Application Utilities also can be used to apply a 2010 snapshot of water use for the DRB; a factorial approach enables scenario testing of increased or decreased water use for each simulation. Finally, the WATER Application Utilities can be used to reformat streamflow time series for input to statistical or reservoir management software.

\section{Introduction}

Development of the Water Availability Tool for Environmental Resources (WATER) for the Delaware River Basin (DRB) was done as part of the U.S. Geological Survey (USGS) Water Census focus area study. This work is part of implementation of the U.S. Department of the Interior Secure Water Act to Sustain and Manage America's Resources for Tomorrow (WaterSMART, http://water.usgs.gov/watercensus/ WaterSMART.html). WATER-DRB addresses multiple aspects of this work by providing a foundation to better understand streamflow, water use, and ecological water needs both for current conditions and for those associated with forecasted climate change and population expansion.

This report summarizes those data used to inform the model and describes how this decision support system (DSS) has been integrated with general circulation models (GCMs) and urbanization forecasts to provide resource managers with a way to objectively and consistently investigate water-management strategies. This report is separated into three sections:

1. This first section, "Focus Area and Geographic Limitations," summarizes data sources, geographic extent of the DSS, and uncertainty associated with streamflow simulations.

2. The second section, "Instruction Manual for WATER," explains how to install and use the WATER DSS.

3. The third section, "Instruction Manual for WATER Application Utilities," explains how to install and use the WATER Application Utilities package.

For more detailed information about data sources, model development, the statistical evaluation process for streamflow simulations, and the uncertainty associated with streamflow simulation for historical and future time periods, see Williamson and others (2015). 


\section{Section 1. Focus Area and Geographic Limitations}

The DRB encompasses $35,075 \mathrm{~km}^{2}\left(13,539 \mathrm{mi}^{2}\right)$ and includes parts of Delaware, Maryland, New Jersey, New York, and Pennsylvania, including the population centers of Wilmington, Delaware; Philadelphia, Pennsylvania; and Trenton, New Jersey (fig. 1). The DRB occupies 0.4 percent of the continental United States, but provides water for 15 million people, about 5 percent of the U.S. population. The WATER DSS developed for the DRB includes the entire basin; however, there are some areas where WATER can provide general streamflow information but should be used cautiously. For example, WATER does not provide a method for simulating the influence of tides on streamflow, as would be expected in stream reaches downstream of Trenton along the Delaware River and in tributaries draining directly into Delaware Bay (fig. 2). Additionally, WATER does not incorporate controlled releases from dams and reservoirs in the Basin, so WATER will not accurately simulate flows on large rivers affected by these releases. This includes, in particular, the entire length of the main-stem Delaware River, but also parts of the East and West Branches of the Delaware River; Neversink, Lackawaxen, Mongaup, Lehigh, Musconectcong, Schuylkill, and Brandywine Rivers; as well as other locations (fig. 2). In anticipation of this constraint, WATER was designed to output streamflow simulations at river locations known to be inflow points for the Delaware River Basin Commission's DRBPlanning Support Tool (PST) that incorporates the Operational Analysis and Simulation of Integrated Systems (OASIS) simulation software (http://hydrologics.net/oasis.html). If WATER is used to simulate streamflow for areas that include reservoirs, they will be treated as any other water body. Consequently, users should be familiar enough with their area of interest to understand whether or not streamflow is controlled by reservoir management.

\section{Data Sources Provided with WATER and WATER Application Utilities}

The DRB WATER DSS, referred to as "WATER" hereinafter, uses a process-based hydrologic model that was implemented with a spatial dataset that quantifies spatial variability in topography, climate, soil properties, and anthropogenic features that affect natural water movement in this five-state area (fig. 1). Although WATER was developed and implemented using historical data, the ultimate goal was to provide a DSS that could simulate streamflow under a broad range of forecasted climatic and land-use scenarios. Historical streamflow is simulated for 1981-2011, using the National Land Cover Database (NLCD), Soil Survey Geographic Database (SSURGO), and Daymet precipitation and temperature data (table 1). All spatial data are in the North American Datum of 1983 Albers Equal Area Projection using the Geodetic Reference System 1980 Spheroid. Because WATER has been designed to use a standard set of data sources that are available for the entire study area, snowpack and potential evapotranspiration (PET) were both simulated in the DSS using a temperature indexed approach (Hamon, 1963).

WATER also interacts with a scenario building tool (WATER Application Utilities) that provides a range of general circulation model (also known as global circulation model or global climate model; GCM) datasets that can be used to synthesize a climate record for forecasted future conditions, including two scenarios as characterized by the representative concentration pathways (RCPs) (tables 2 and 3). WATER incorporates the change factor $(\delta)$ approach and provides data for temperature, precipitation, and PET. The scenario builder also applies the water use (table 4) and reformats the simulated flow record into the desired output structure. To provide for reservoir management planning, streamflow simulations can be completed for inflow points to the reservoirs and formatted in the output required by the reservoir management model, DRB-PST, used by the Delaware River Basin Commission. 


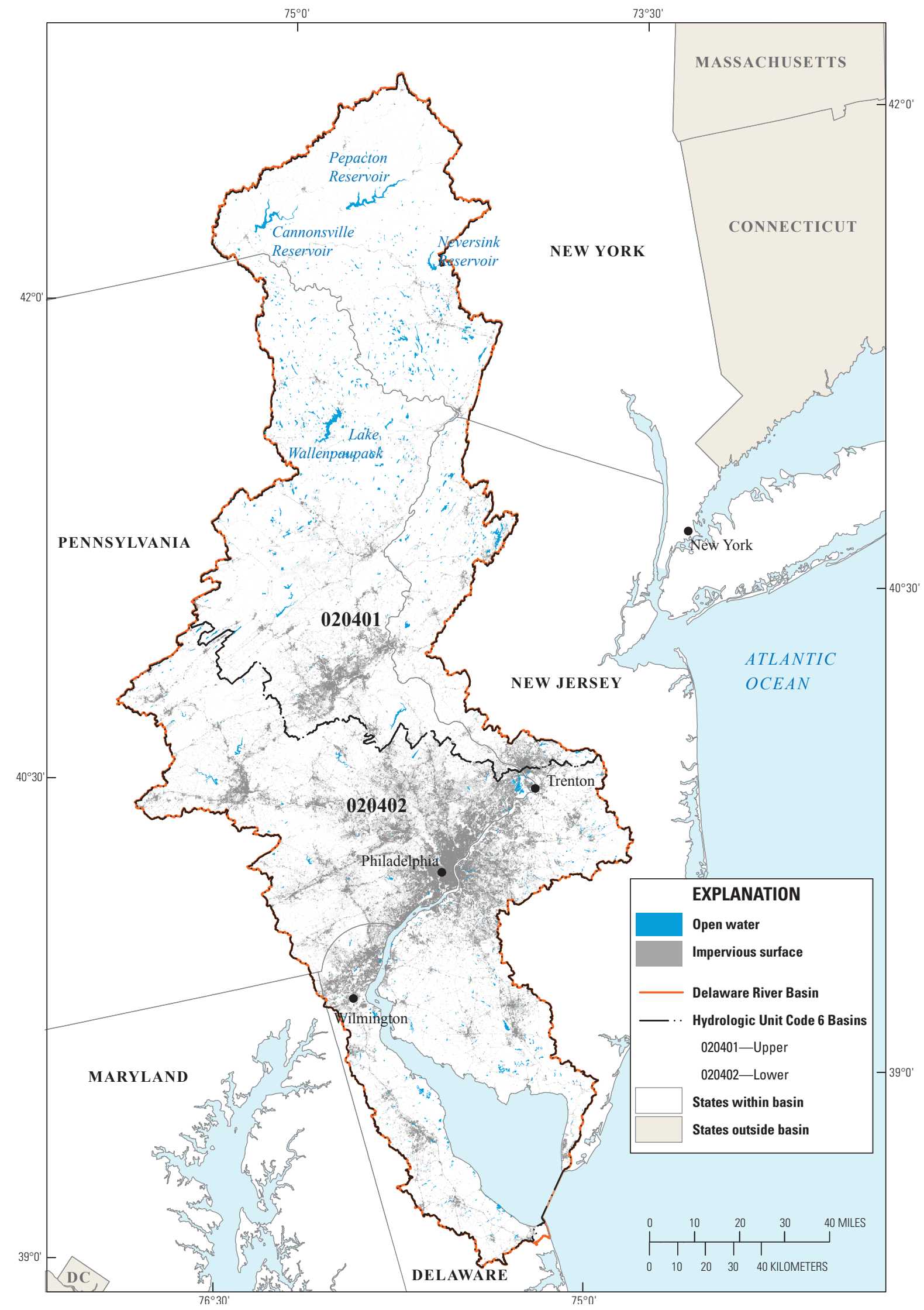

Figure 1. The Delaware River Basin, including parts of Delaware, New Jersey, New York, and Pennsylvania, as well as a small part of Maryland. Major population centers and reservoirs in the upper basin also are shown. 


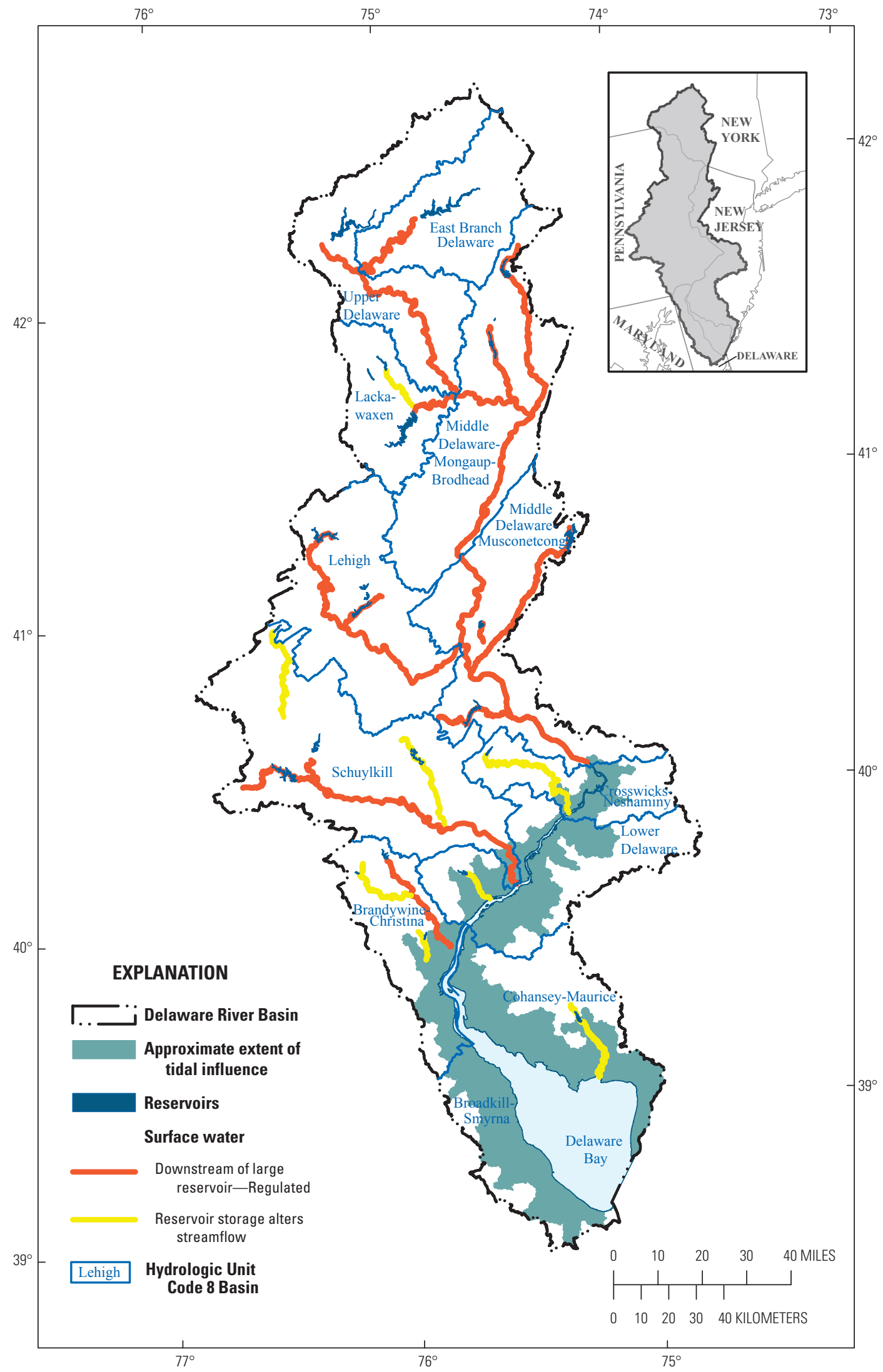

Table 2. Parts of Delaware River system where caution should be used because of stream regulation and tidal influences. 
Table 1. Data sources and citations for the Delaware River Basin Water Availability Tool for Environmental Resources.

[WATER, Water Availability Tool for Environmental Resources; SSURGO, Soil Survey Geographic; NRCS, Natural Resources Conservation Service; DEM, digital elevation model; TWI, topographic wetness index; HRU, hydrologic response unit]

\begin{tabular}{ll}
\hline \multicolumn{1}{c}{ Data source } & \multicolumn{1}{c}{ Contribution to WATER } \\
\hline $\begin{array}{l}\text { Daymet (Thornton and others, 2012) } \\
\text { http://daymet.ornl.gov/index.html }\end{array}$ & Daily temperature and precipitation data for 1980-2011. \\
$\begin{array}{l}\text { National Elevation Dataset } \\
\text { (Gesch and others, 2002) }\end{array}$ & $\begin{array}{c}\text { Elevation data (as DEM) used for basin delineation and } \\
\text { TWI calculations. }\end{array}$ \\
http://ned.usgs.gov/ & HRUs and impervious area. \\
$\begin{array}{l}\text { 2011 National Land Cover Database } \\
\text { (Jin and others, 2013) } \\
\text { http://www.mrlc.gov/ }\end{array}$ & \\
$\begin{array}{l}\text { Soil Survey Geographic (SSURGO) database } \\
\text { (SSURGO; Soil Survey Staff, 2014) } \\
\text { http://datagateway.nrcs.usda.gov/ }\end{array}$ & $\begin{array}{c}\text { Hydrologic soil characteristics and TOPMODEL specific } \\
\text { parameters. }\end{array}$ \\
\hline
\end{tabular}

Table 2. General circulation models provided as part of the Water Availability Tool for Environmental Resources database. The differences among models are detailed by Forster and others (2013).

\begin{tabular}{|c|c|c|c|c|}
\hline Source & Abbreviation & $\begin{array}{c}\text { General } \\
\text { circulation } \\
\text { model }\end{array}$ & $\begin{array}{c}\text { Tile size } \\
\text { (kilometers) }\end{array}$ & Documentation \\
\hline $\begin{array}{l}\text { National Oceanic and Atmospheric Administration } \\
\text {-Geophysical Fluid Dynamics Laboratory }\end{array}$ & GFDL_NOAA & ESM2G & 200 & $\begin{array}{l}\text { Dunne and others } \\
\text { (2012). }\end{array}$ \\
\hline $\begin{array}{l}\text { National Aeronautics and Space Administration } \\
\text { - Goddard Institute for Space Studies }\end{array}$ & GISS & E2-H & 220 & $\begin{array}{l}\text { Nazarenko and others } \\
\text { (2015). }\end{array}$ \\
\hline $\begin{array}{l}\text { National Center for Atmospheric Research } \\
\text { - Community Climate System Model }\end{array}$ & NCAR_CCSM4 & CCSM4 & 105 & Gent and others (2011). \\
\hline $\begin{array}{l}\text { Canadian Centre for Climate Modelling and } \\
\text { Analysis }\end{array}$ & CanESM2 & CGCM4 & 310 & $\begin{array}{l}\text { von Salzen and others } \\
\text { (2013). }\end{array}$ \\
\hline
\end{tabular}

Table 3. Representative concentration pathways (RCPs; summarized from van Vuuren and others, 2011)—data are provided for RCPs 4.5 and 8.5 (bolded). For comparison, the January 2015 global mean carbon dioxide $\left(\mathrm{CO}_{2}\right)$ concentration was 400.14 parts per million (ppm), up from 397.42 ppm in January 2014 (Earth System Research Laboratory, 2015; verified March 25, 2015).

[RCP, representative concentration pathway; $\mathrm{W} / \mathrm{m}^{2}$, watts per square meter; ppm, parts per million]

\begin{tabular}{clc}
\hline $\begin{array}{c}\text { Representative concentration } \\
\text { pathway }\end{array}$ & \multicolumn{1}{c}{ Radiative forcing } & $\begin{array}{c}\text { Approximate carbon dioxide } \\
\text { concentration }\end{array}$ \\
\hline RCP 8.5 & Rising radiative forcing to $8.5 \mathrm{~W} / \mathrm{m}^{2}$ by 2100 & $1,370 \mathrm{ppm} \mathrm{CO}^{2}$ \\
RCP 6 & Stabilization at $6 \mathrm{~W} / \mathrm{m}^{2}$ after 2100 & $850 \mathrm{ppm} \mathrm{CO}^{2}$ \\
RCP 4.5 & Stabilization at $4.5 \mathrm{~W} / \mathrm{m}^{2}$ at 2100 & $650 \mathrm{ppm} \mathrm{CO}^{2}$ \\
RCP 2.6 & $\begin{array}{c}\text { Peak at about } 3 \mathrm{~W} / \mathrm{m}^{2} \text { before } 2100 \text { and then } \\
\text { decline to } 2.6 \mathrm{~W} / \mathrm{m}^{2} \text { by } 2100\end{array}$ & $490 \mathrm{ppm} \mathrm{CO}^{2}$ \\
\hline
\end{tabular}


Table 4. Water-use categories and geospatial data type provided from 2010 National Water Census Inventory.

[Data from Hutson and others, in press]

\begin{tabular}{llcc}
\hline Water-use category & \multicolumn{3}{c}{ Geospatial data type } \\
\cline { 2 - 4 } & $\begin{array}{c}\text { Surface water } \\
\text { or groundwater }\end{array}$ & $\begin{array}{c}\text { Withdrawal } \\
\text { or return }\end{array}$ & $\begin{array}{c}\text { Point data } \\
\text { or areal average }\end{array}$ \\
\hline Aquaculture & Both & Withdrawal & Point. \\
\hline Commercial & Both & Withdrawal & Point. \\
\hline Domestic self-supply & Groundwater & Withdrawal & Areally \\
averaged.
\end{tabular}

\section{Uncertainty in Simulations and Relation to Scenario Investigation}

The WATER DSS has been developed to provide the DRB community with an ability to assess the potential effect of different management decisions, forecasted changes in climate, and land-cover change on streamflows throughout the DRB using a process-based model that accounts for physical processes known to influence streamflow. WATER provides a consistent framework for simulation of hydrologic conditions, including high and low flows, for basins characterized by a range of size, land cover, and location within the DRB. The individual hydro-climatic components of the water budget, including evapotranspiration and snow accumulation and melt, also are effectively simulated by the WATER DSS. Because the WATER DSS relies on a mechanistic approach to predict streamflow, this regionally calibrated DSS can be used to investigate the sustainability and resiliency of water resources resulting from forecasted environmental and management scenarios. Ultimately, it is the responsibility of the user to interpret results. However, some precautions and suggestions for use of the DSS follow (Williamson and others, 2015):

1. An uncertainty of $+2 /-1$ average Normalized Root Mean Squared Error $\left(\mathrm{RMSEn}_{57}\right)$ of 0.939 is recommended for daily flow simulations. This uncertainty is averaged from the confidence interval of streamflow simulation for 57 basins used in optimization of WATER (Williamson and others, 2015).

4. For those scenarios that rely on GCM data and landcover change, mean monthly streamflows rather than daily streamflows should be used. This constraint on the temporal resolution of streamflows stems from the fact that GCM change factors use a monthly normal, and land-cover simulations were derived at a decadal time-step. Because temporal resolution of streamflows should not be finer than the resolution of input GCM data, normalized mean monthly streamflow (that is, averaged for each month for the 25-year climate record) should be used with the mean RMSEn for mean monthly streamflows (0.3255) to quantify the forecasted range of streamflow and water availability for a given scenario.

5. All scenarios should be compared to simulation of the same site using the "historical conditions" (2011 NLCD and 2010 water use) provided with the DSS. This is similar to the approach of GCM change-factor calculations. Multiple GCMs and RCPs should be incorporated into scenario testing and the overall trend in streamflow and other hydroclimatic variables among multiple GCM simulations should be used to plan for forecasted change.

\section{References Cited (for all sections)}

Beven, K.J., and Kirkby, M.J., 1979, A physically based, variable contributing area model of basin hydrology / Un modèle à base physique de zone d'appel variable de l'hydrologie du bassin versant: Hydrological Sciences Bulletin, v. 24, no. 1, p. 43-69. 
Dunne, J.P., John, J.G., Adcroft, A.J., Griffies, S.M., Hallberg, R.W., Shevliakova, E., Stouffer, R.J., Cooke, W., Dunne, K.A., Harrison, M.J., Krasting, J.P., Malyshev, S.L., Milly, P.C.D., Phillipps, P.J., Sentman, L.T., Samuels, B.L., Spelman, M.J., Winton, M., Wittenberg, A.T., and Zadeh, N., 2012, GFDL's ESM2 Global Coupled Climate-Carbon Earth System Models_-Part I-Physical formulation and baseline simulation characteristics: Journal of Climate, v. 25 , no. 19 , p. 6646-6665.

Forster, P.M., Andrews, T., Good, P., Gregory, J.M., Jackson, L.S., and Zelinka, M., 2013, Evaluating adjusted forcing and model spread for historical and future scenarios in the CMIP5 generation of climate models: Journal of Geophysical Research-Atmospheres, v. 118, no. 3, p. 1139-1150.

Gent, P.R., Danabasoglu, G., Donner, L.J., Holland, M.M., Hunke, E.C., Jayne, S.R., Lawrence, D.M., Neale, R.B., Rasch, P.J., Vertenstein, M., Worley, P.H., Yang, Z.-L., and Zhang, M., 2011, The Community Climate System Model Version 4: Journal of Climate, v. 24, no. 19, p. 4973-4991.

Gesch, D., Oimoen, M., Greenlee, S., Nelson, C., Steuck, M., and Tyler, D., 2002, The National Elevation Dataset: Photogrammetric Engineering and Remote Sensing, v. 68, no. 1.

Hamon, W.R., 1963, Estimating potential evapotranspiration: Transactions of the American Society of Civil Engineers, v. 128 , no. 1 , p. $324-337$.

Hutson, S.S., Linsey, K.S., Ludlow, R.A., Reyes, B., and Shourds, J.L., in press, Estimated Use of Water in the Delaware River Basin in Delaware, New Jersey, New York, and Pennsylvania, 2010: U.S. Geological Survey Scientific Investigations Report 2015-5142.

Jin, S., Yang, L., Danielson, P., Homer, C., Fry, J., and Xian, G., 2013, A comprehensive change detection method for updating the National Land Cover Database to circa 2011: Remote Sensing of Environment, v. 132, p. 159-175.

Kennen, J.G., Kauffman, L.J., Ayers, M.A., Wolock, D.M., and Colarullo, S.J., 2008, Use of an integrated flow model to estimate ecologically relevant hydrologic characteristics at stream biomonitoring sites: Ecological Modelling, v. 211, nos. $1-2$, p. 57-76.

Nazarenko, L., Schmidt, G.A., Miller, R.L., Tausnev, N., Kelley, M., Ruedy, R., Russell, G.L., Aleinov, I., Bauer, M., Bauer, S., Bleck, R., Canuto, V., Cheng, Y., Clune, T.L., Del Genio, A.D., Faluvegi, G., Hansen, J.E., Healy, R.J., Kiang, N.Y., Koch, D., Lacis, A.A., LeGrande, A.N., Lerner, J., Lo, K.K., Menon, S., Oinas, V., Perlwitz, J., Puma, M.J., Rind, D., Romanou, A., Sato, M., Shindell, D.T., Sun, S., Tsigaridis, K., Unger, N., Voulgarakis, A., Yao, M.S., and Zhang, J., 2015, Future climate change under RCP emission scenarios with GISS ModelE2: Journal of Advances in Modeling Earth Systems, v. 7, no. 1, p. 244-267.
Natural Resources Conservation Service, 2014, Web Soil Survey_-gSSURGO: U.S. Department of Agriculture, Natural Resources Conservation Service, accessed January 22, 2015, at http://websoilsurvey.nrcs.usda.gov/.

Thompson, J., and Archfield, S., 2014. The EflowStats R package, USGS, accessed August 4, 2015, at https://github.com/ USGS-R/EflowStats.

Thornton, P.E., Thornton, M.M., Mayer, B.W., Wilhelmi, N., Wei, Y., and Cook, R.B., 2012, Daymet-Daily surface weather on a $1 \mathrm{~km}$ grid for North America, 1980-2012: Oak Ridge, Tennessee, Oak Ridge National Laboratory Distributed Active Archive Center dataset.

U. S. Department of Agriculture [USDA], 1986, Urban hydrology for small watersheds: Natural Resources Conservation Service, U.S. Department of Agriculture 55.

van Vuuren, D., Edmonds, J., Kainuma, M., Riahi, K., and Weyant, J., 2011, A special issue on the RCPs: Climatic Change, v. 109, nos. 1-2, p. 1-4.

von Salzen, K., Scinocca, J.F., McFarlane, N.A., Li, J., Cole, J.N.S., Plummer, D., Verseghy, D., Reader, M.C., Ma, X., Lazare, M., and Solheim, L., 2013, The Canadian Fourth Generation Atmospheric Global Climate Model (CanAM4) - Part I-Representation of physical processes: Atmosphere-Ocean, v. 51, no. 1, p. 104-125.

Williamson, T.N., Lant, J.G., Claggett, P., Nystrom, E., Milly, P.C.D., Nelson, H., Hoffman, S., Colarullo, S., and Fischer, J., 2015, Summary of hydrologic modeling for the Delaware River Basin using the Water Availability Tool for Environmental Resources (WATER): U.S. Geological Survey Scientific Investigations Report 2015-5143, 68 p., at http://dx.doi.org/10.3133/sir2015/5143.

Williamson, T.N., Odom, K.R., Newson, J.K., Downs, A.C., Nelson Jr., H.L., Cinotto, P.J., and Ayers, M.A., 2009, The Water Availability Tool for Environmental Resources (WATER) - A water-budget modeling approach for managing water-supply resources in Kentucky-Phase I-Data processing, model development, and application to nonkarst areas: U.S. Geological Survey Scientific Investigations Report 2009-5248, 34 p., accessed July 7, 2012, at http://pubs.usgs.gov/sir/2009/5248/.

Williamson, T.N., Taylor, C.J., and Newson, J.K., 2013, Significance of exchanging SSURGO and STATSGO data when modeling hydrology in diverse physiographic terranes: Soil Science Society of America Journal, v. 77, no. 3, p. 877-889, https://pubs.er.usgs.gov/publication/70046394.

Wolock, D.M., 1993, Simulating the variable-source-area concept of streamflow generation with the watershed model TOPMODEL: U.S. Geological Survey Water-Resources Investigations Report 93-4124, 33 p, accessed November 12, 2012, at http://pubs.er.usgs.gov/publication/wri934124. 


\section{Section 2. Instruction Manual for WATER}

\section{Using the Water Availability Tool for Environmental Resources (WATER)}

The WATER decision-support system (DSS) combines the geospatial information technology (GIS) functionality with a physically based hydrologic model to estimate streamflow across the Delaware River Basin (DRB). The physically based model is based on TOPMODEL, which is a semi-distributed watershed model that simulates the variable-source-area concept of streamflow generation (Beven and Kirkby, 1979; Wolock, 1993; Kennen and others, 2008; Williamson and others, 2009, 2013). The application was developed to provide a consistent and defensible method of estimating streamflow and water availability for historical and forecasted conditions (that is, climate and land-use change). Additional information about this and associated work is available at the USGS National Water Census DRB Web page (http://water.usgs.gov/watercensus/delaware.html).

The three steps to installing WATER are (1) copying the database, (2) installing the program, and (3) initializing the program; these steps are described in detail in the instructions that follow. After installation is complete, WATER can be used to simulate historical streamflow throughout the DRB. Simulation of forecasted conditions using land-cover data sets provided with WATER require the user to make changes in the anthropogenic folder. Incorporation of water use requires post-processing using the WATER Application Utilities that are described in the final section of this report. Streamflow simulation using forecasted climate data provided with WATER requires a historical simulation (which one can use as a baseline) that is then post-processed using the WATER Application Utilities before being re-run with WATER with the forecasted climatic record.

\section{Before You Install}

To install the WATER DSS successfully, the ESRI ArcINFO ${ }^{\mathrm{TM}} 10.0$ with an individual Spatial Analyst extension must be installed on every end user machine to which the WATER application is to be installed:

- Go to the Start menu $\rightarrow$ All Programs $\rightarrow$ ArcGIS $\rightarrow$ ArcGIS Administrator;

- Select the Availability folder and look for Spatial Analyst.

If your system is administered by someone other than yourself, you will need administrative access to install the program.

\section{Installation Instructions}

1. Determine where you will be storing the database (about $22 \mathrm{~GB}$ ) and simulations folders - the local C: drive is recommended. The model will run faster if these folders can be stored on your local hard drive as opposed to an external or network drive.

A. Create a $U S G S$ folder where you plan to store the database and simulations.

B. Copy the database into the USGS folder. Be sure to keep a back-up copy of the database in another location.

C. Your file structure should look like figure 3 .

D. The database on which the program depends is in the water_ $d b$ folder.

E. The simulations folder is where individual simulations will be stored until you either delete them or move them to a different location. This folder can get very large, so you may want to store completed simulations elsewhere.

F. The extMod folder is for storage of any external program that needs to be accessed by the DSS. It is likely that your extMod folder is empty.

G. If there are no simulations or extMod folders in your water folder, create them.

H. Confirm that the entire database has copied by comparing the size of the $\boldsymbol{U S G S}$ folder on your local drive to the size of the corresponding folder on the source drive. 


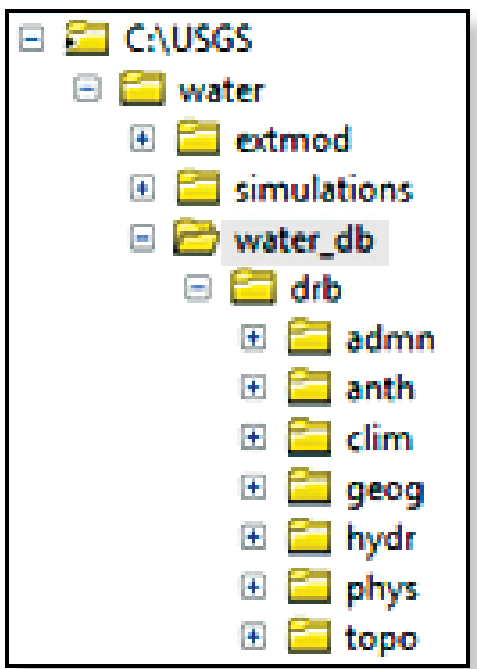

Figure 3. File structure required for WATER database.

2. Copy the $W A T E R \_<$date $>$folder to your desktop, where $<$date $>$denotes the date when the software was last revised. Please save this file for reference.

A. This folder is likely zipped, so it will need to be extracted.

B. Open and click the setup executable to begin the installation process.

3. Depending on your security settings, you may see a Security Warning dialog box. Click Install to install the application (fig. 4).

4. Accept the suggested/default location for installation of the program.

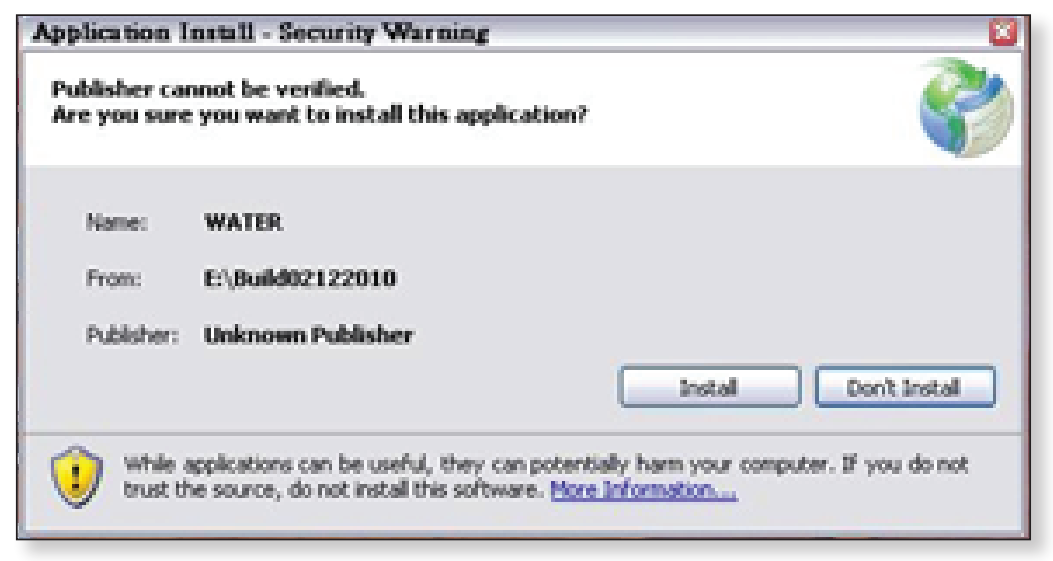

Figure 4. Installation warning for installing program.

\section{Initialization Instructions}

A short-cut should display in your Start menu: DRB WATER.

5. When you start the program for the first time, it undergoes initialization — checking for up-to-date licenses, necessary folder locations, and required data files.

6. The DSS requests the main root directory. Navigate to and select the USGS folder (discussed in step 1 of section, "Installation Instructions") requested by the program. If the remaining subfolders within the water folder have remained intact, the application will finish loading. If any subfolders are missing, navigate to the folder locations within the Browse For Folder dialog box. 
Note: If the application requests the location of these folders each time the DSS is opened, then:

A. Identify the Programs/subfolder into which the application has loaded.

B. Uninstall the application using the installation package or your Control Panel.

C. Confirm that the WATER.exe... 1 1.0.0.0 \user.config file and folder have been deleted from the C: $\backslash$ Users $\backslash$ YourName $\backslash$ AppData\Local\US_Geological_Survey folder.

D. Confirm the integrity of the USGS folder and restart your computer.

E. Reinstall the application into the default directory, paying special attention to navigating to the water subfolder process (step 6, above).

\section{Running the Water Application}

After the initialization process, WATER should start without any need to relocate these data.

1. Start the program from the Start menu.

2. You will see an index map of the entire DRB (fig. 5).

3. Access and select the magnification tool from the Zoom dropdown menu (fig. 5).

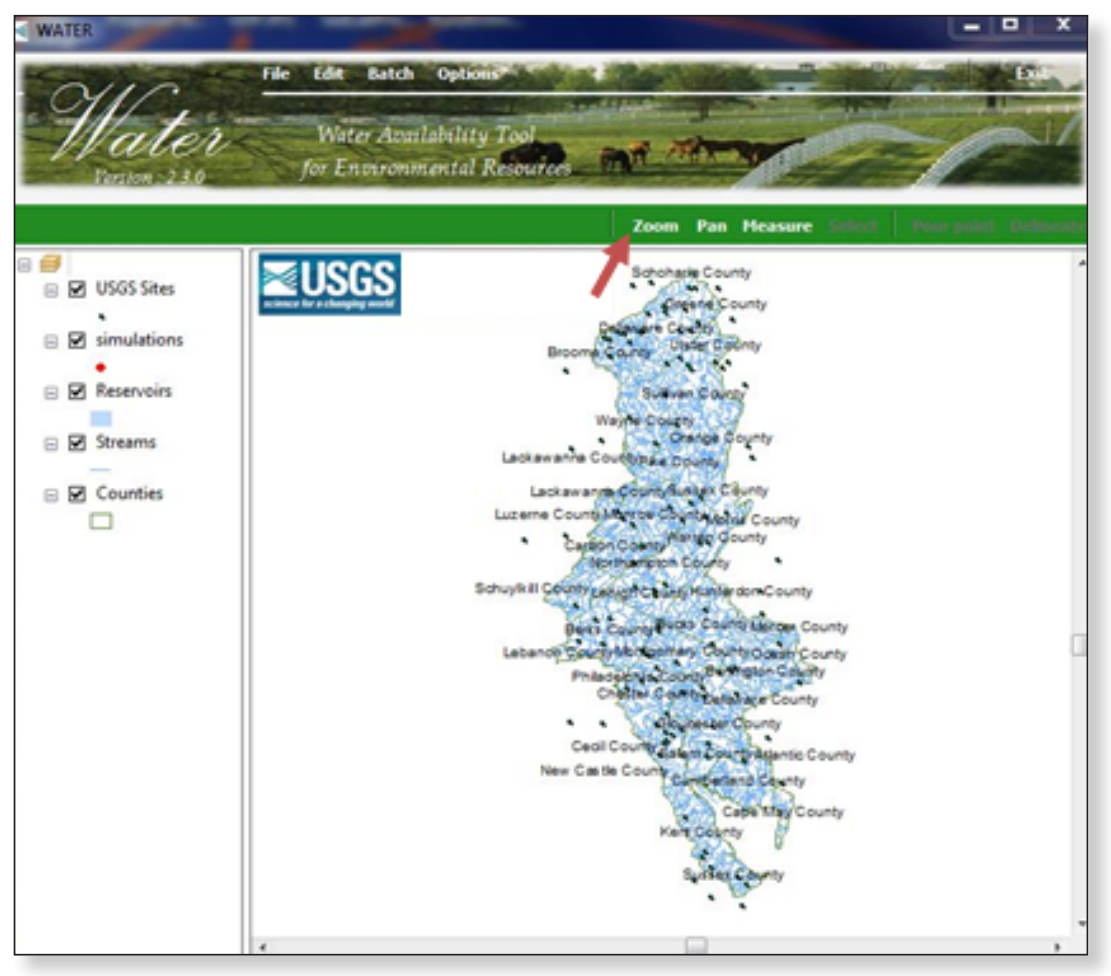

Figure 5. Index map of Delaware River Basin.

4. You can either drag the magnification tool over an area of interest or click in a single location on the map. Note: The DSS will only delineate a watershed for pour points that are on the blue streamline that is visible on the map.

5. Continue this process over your area of interest until the Pour Point button becomes enabled. Click Pour Point. You can hover over the stream reach to confirm the location (fig. 6).

Note: Zooming in and out can cause the high-resolution stream network to be disabled. If this occurs, please restart the program. 


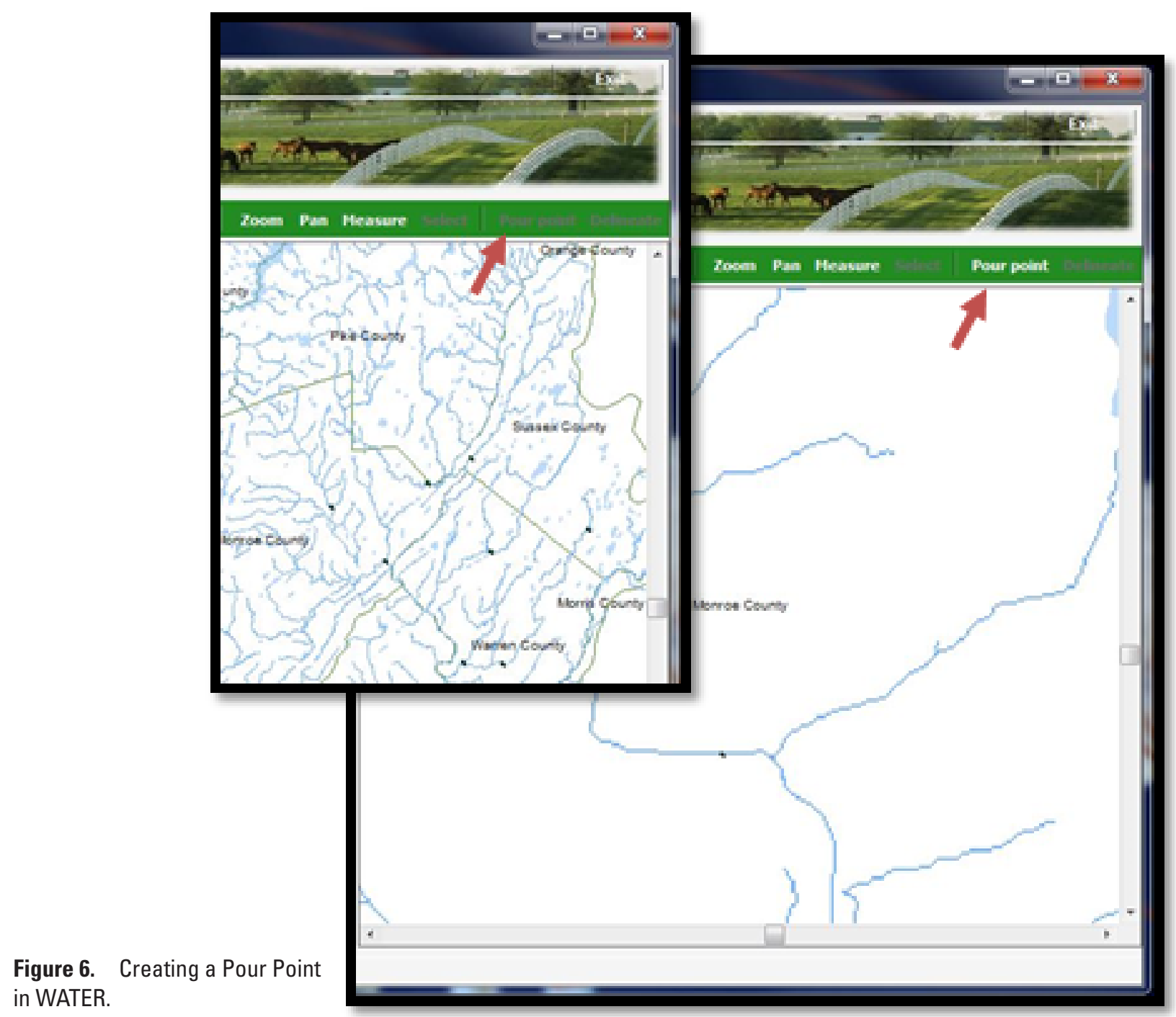

6. Click the desired location for the pour point (the most downstream point of your basin of interest) within any stream raster cell. If the pour point is not located on a stream raster cell, it will NOT be delineated, the Simulation Information dialog box will not display, and you will need to click a stream cell to assign the pour point location.

7. If the pour point you select is located on a stream-raster cell, a dialogue box (fig. 7) will become visible - this is where you name your simulation and attach any notes (12 or fewer characters). Logical details to include in your simulation name include:
A. Basin name,
B. Date,
C. Project, and
D. Your initials if you are sharing a simulations folder.

Although much of this information is stored as part of the simulation, it can be useful to see it without opening the simulation and DSS. 
8. Accept the simulation. The Delineate button will now be enabled. Click Delineate (fig. 7).

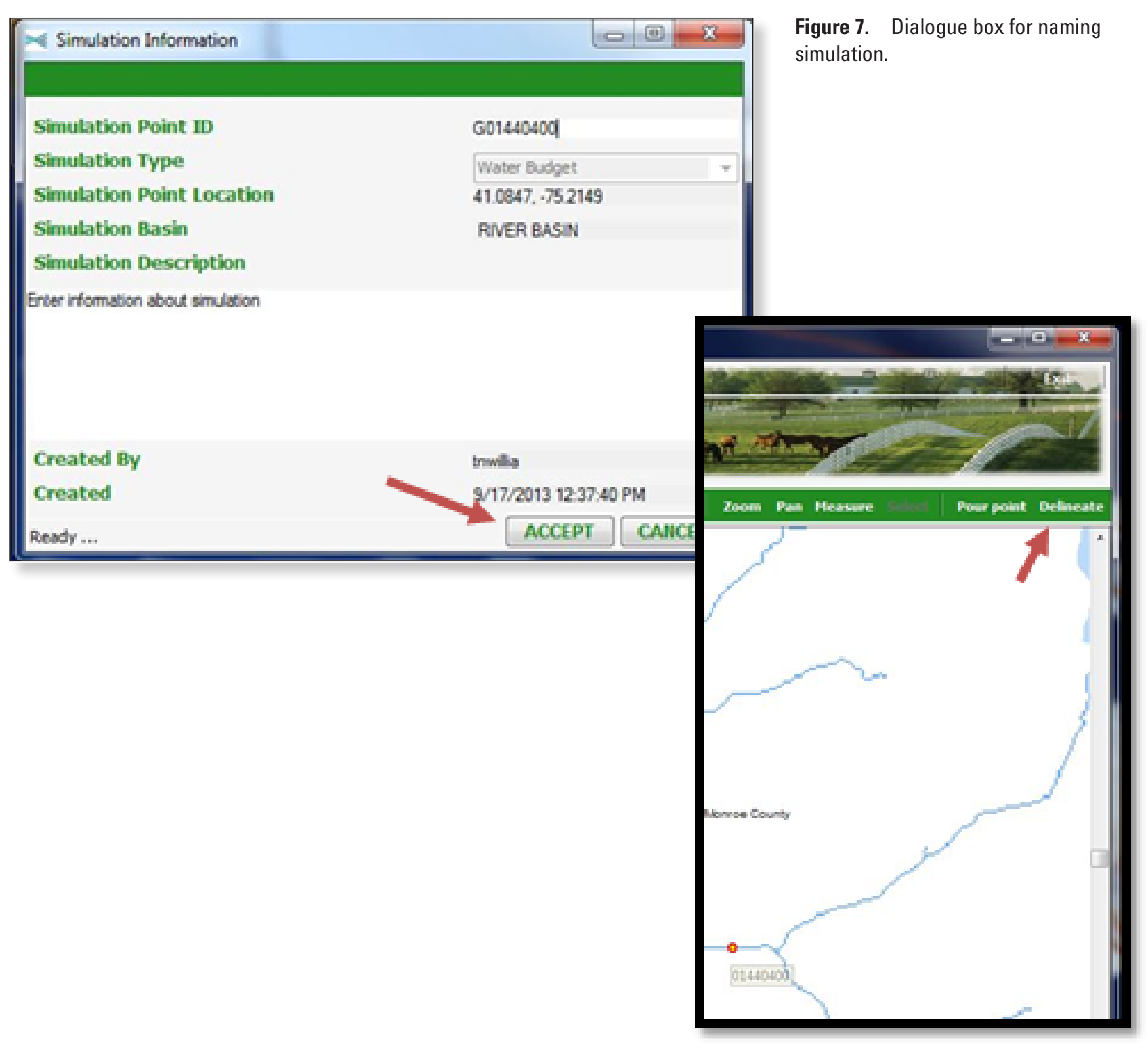

9. The program will begin to delineate your basin of interest (based on the 10-m digital elevation model [DEM] included in the database). You will see the green bar moving back and forth at the bottom of the window. Depending on the type of system you are running, the location of the database, and the basin size, this will take several minutes. For example, delineation of a $200-\mathrm{km}^{2}$ basin takes about 5 minutes on most systems. 
10. When the process is complete, you will see an outline of the basin. You must now click Load Data to load the provided data sets needed to estimate spatially averaged characteristics within the delineated basin (fig. 8). You will know this is complete when the Run button appears.

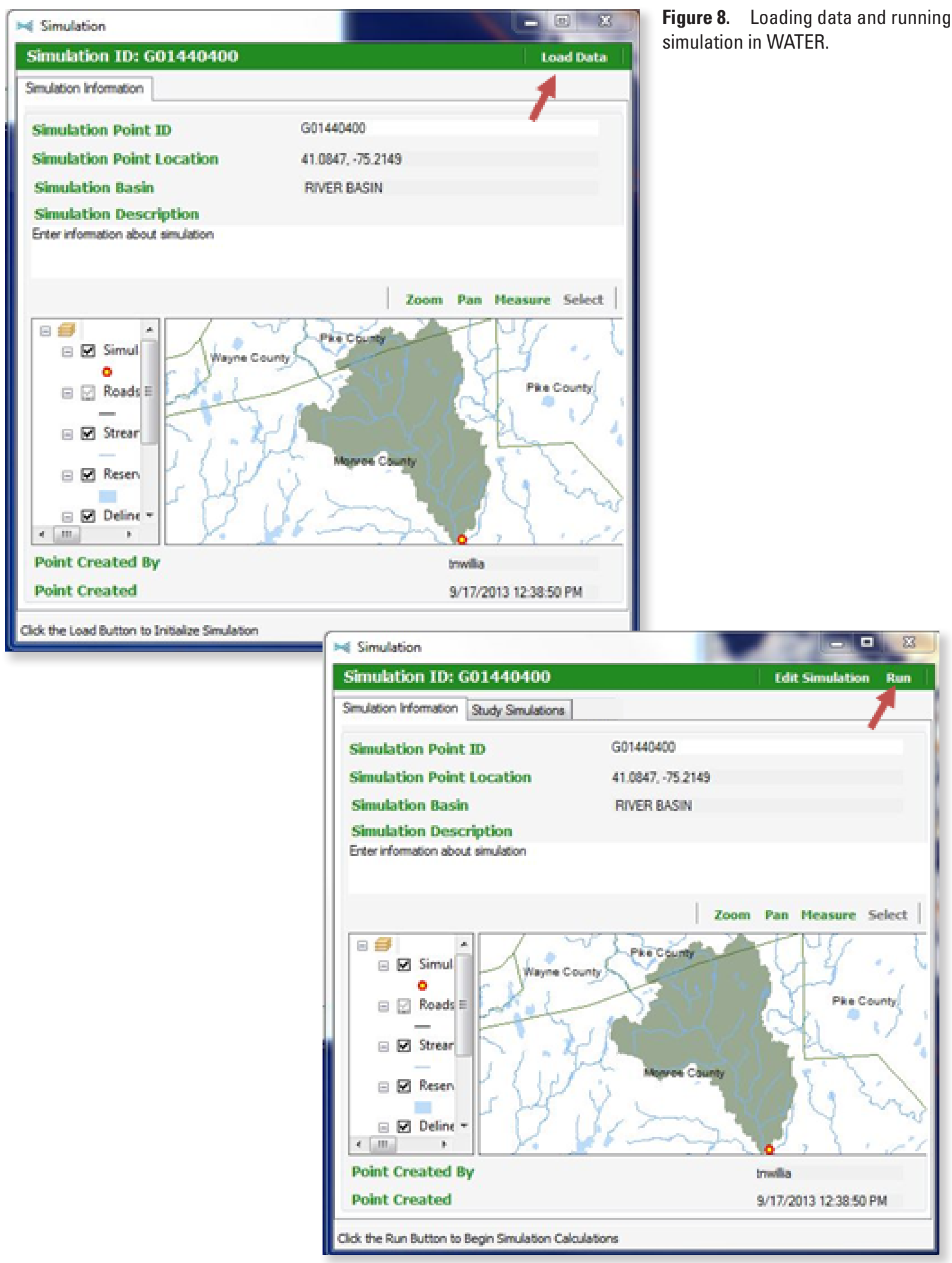


11. The DSS will now gather and load those data necessary to run the hydrologic model, including climate data, land-cover distributions (Forested, Agricultural, Developed), soil characteristics, and topography. Similar to the basin delineation step, this can take several minutes depending on the size of the delineated basin.

12. When those data have been loaded, spatially-averaged basin characteristics and parameters for each land-cover type become available (fig. 9). The Study Summary on the Study Simulations page will be blank until after the model is run.

\begin{tabular}{|c|c|c|}
\hline \multicolumn{3}{|l|}{ N Simulation } \\
\hline \multicolumn{2}{|l|}{ Sinulation ID: G01440400 } & Edit Simulation View * \\
\hline Semulstion Vifomstion & Study Smulations PEST & \\
\hline Study Overview Forest Agroutu & ural | Unalocated & Hydrograph \\
\hline Smulsion Aerbutes & Sinulation Tme Series & Simulution Teosgrophic hdices \\
\hline Atrbute & Mean Value & Description \\
\hline Such Unt Tots Anos & 161.1486 & (6a Km) Sudy und toed areo \\
\hline Total Eatimsted Serean Avea & 1.8191 & (sq Km) Estmated area of stream coverage \\
\hline Total Lake Area & 0.2025 & (sq Km) Estimsted area of liske coverage \\
\hline Lake Decay" & 1.5 & (Itw) Coefficiert for deloying water though lokes... \\
\hline Uplake Avea & 11.6507 & (sa Km) Contbuting area updream of liskes leca.... \\
\hline Ground Water Wehdrawal & 0.0000 & (ond) Ground water wthdraws \\
\hline Sutace Water Wehdrawd & 0.0000 & (ond) Surface water withdrawd \\
\hline Sulace Water Dascharge & 0.0000 & (end) Surtace water dacharge \\
\hline Latbude & 41.1867 & (DD) Lathude \\
\hline Conductivity Mutpler & 120050 & () Sol conductivty mutpler \\
\hline Water Halding Capacty & 0.1115 & () Werer helding capacty of the sol \\
\hline Wethess index Adustment & 1.0000 & () Topographic wetness index adustment parame-. \\
\hline Sol Depth & 829.7065 & (mm) Depth of sol \\
\hline Percert Mocropore & 0.2000 & () Percertage of subsudace flow attruted to ma.. \\
\hline Feld Canschy & 0.1547 & () Feld capscty \\
\hline Ssturated Hydraule Conductivity & $1,073.3756$ & $(\mathrm{~mm} / \mathrm{dgy})$ Satursted hydraulc conductivity \\
\hline Porosty & 0.2771 & () Porotity of tod \\
\hline Degth of Rock Zone & 6223400 & (mm) Degth of root ane \\
\hline Scaing Factor M & 70.8219 & $(\mathrm{~mm})$ Sol scaling factor \\
\hline Soxtis Coefficiert & 0.5000 & Drea scalsbility factor \\
\hline Percert lepenvous & 0.0810 & (A) Percert impervious \\
\hline Percent Rosd inpervious & 0.0054 & (A) Percent rosd impervious \\
\hline EHective Inpervious & 0.7 & (4) Elective impervious \\
\hline Impervious Rundil Delyy & 0.1000 & () Factor relveng to deloy of impervious numeth \\
\hline Evapotranspiration Epponert" & 0.5000 & () Evapotranspirstion eponert \\
\hline Snow Met Coetidient & 3.0000 & (mm/DegC) Snow met only temperature index mol. \\
\hline Rain on Snow Mot Coetlioiert & 5.0000 & (mm/DegC) Rain on snew teroerature index meto... \\
\hline Impervious Curve Number & 90 & () Curve number \\
\hline
\end{tabular}

Figure 9. Spatially averaged basin characteristics for the forested part of a basin. 
13. You can now Run the model and calculate the streamflow and water budget (fig. 8). After this step has completed, the Study Summary will be complete and the predicted daily Hydrograph will be available as a new tab under the Study Simulations (fig. 10). You also can examine the predicted hydrograph on a monthly or yearly time-step using the View dropdown menu.

14. A text file of this time series is now in your simulations folder as WATER.txt (fig. 11). To incorporate water use, further examine the simulations, and reformat the file into a daily streamflow record that can be incorporated by other programs, you will need to use the WATER Application Utilities. The WATERSimulation.xml has the details of your simulation, which can be opened with an application such as Microsoft Access ${ }^{\mathrm{TM}}$.

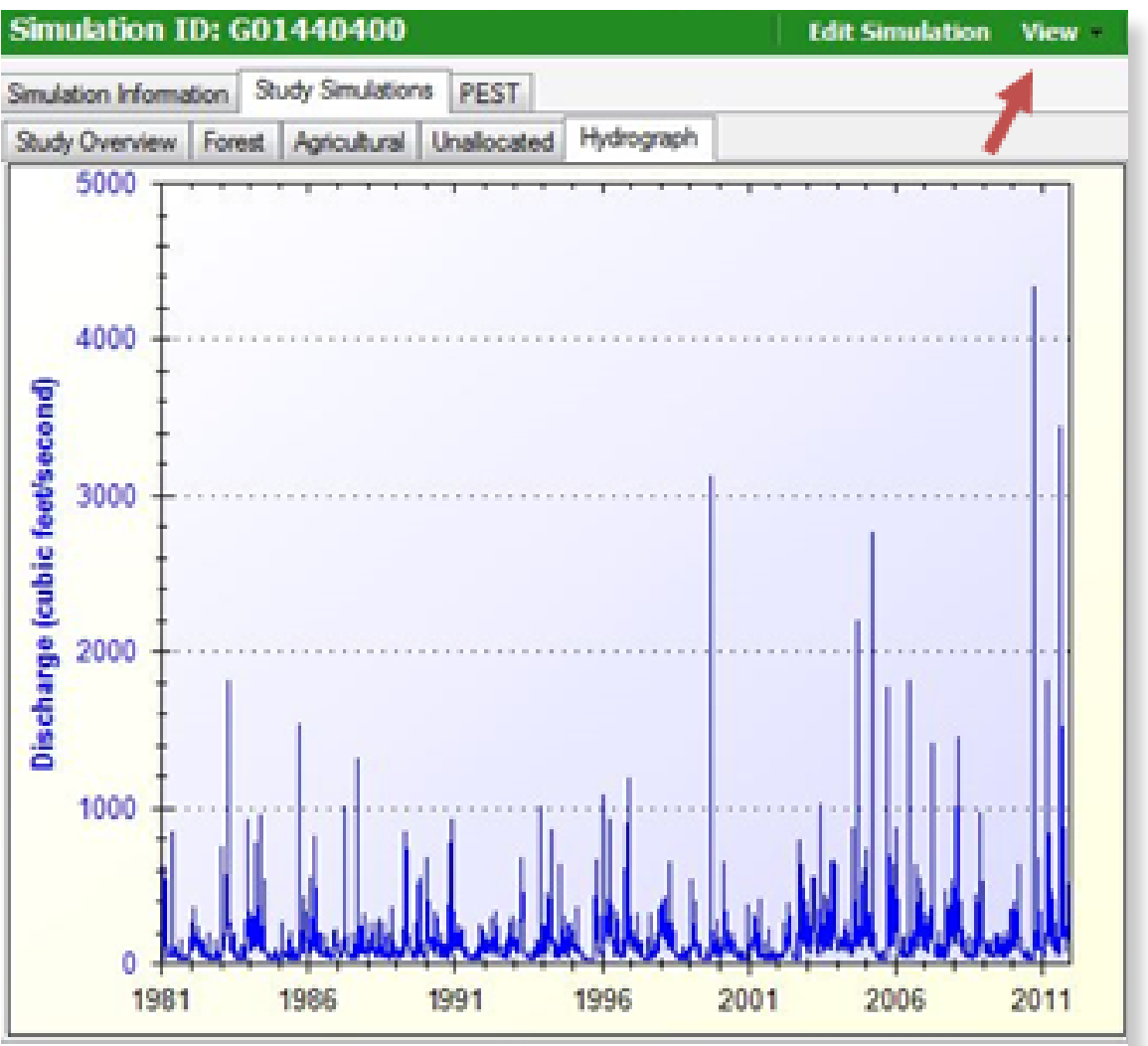

Figure 11. File structure after simulation has been run.

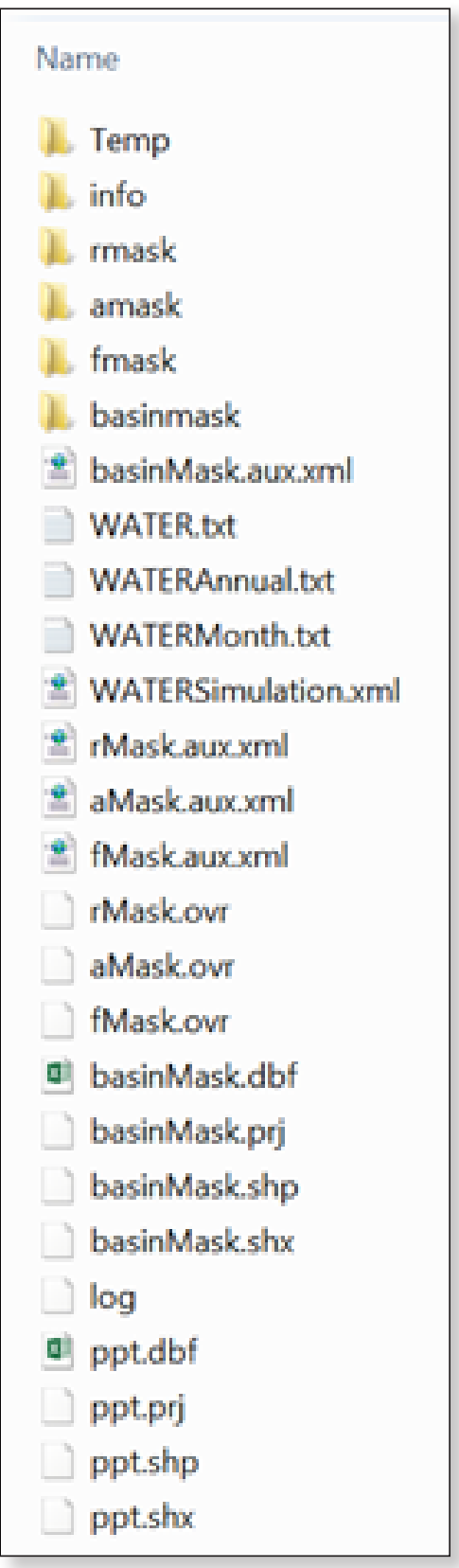




\section{The Batch Mode}

As an alternative, you can run a Batch file of previously delineated basins. This is most effective if the individual basins were constructed using the WATER DSS, because the basin boundaries will coincide with the 10-m DEM raster and there will be no chance of the basin extending beyond the spatial extent of those data layers included in the DSS-for example, this might occur when basins include the headwaters of the DRB and were delineated either by hand from topographic maps or using a coarser-resolution DEM than that used by WATER. If you run a Batch file, you will need to aggregate individual basins into a single shapefile and give them a unique identifier. You also can use a previously delineated set of basins from another source as long as they are in the North American Datum of 1983 Albers Equal Area Projection using the Geodetic Reference System 1980 Spheroid. It is critical that there be no loops in the polygons and that no basins extend beyond the geospatial layers in the WATER database.

1. From the Batch dropdown menu, select New $\rightarrow$ From Shape File (fig. 12).

2. You will need to enter the simulation information (fig. 13):
A. Name the Batch Project,
B. Browse to the desired shapefile of basins,
C. Select the attribute to be used as the Basin Field Name (your identifier), and then
D. Click ACCEPT.

3. Return to the Batch dropdown menu and select Run.

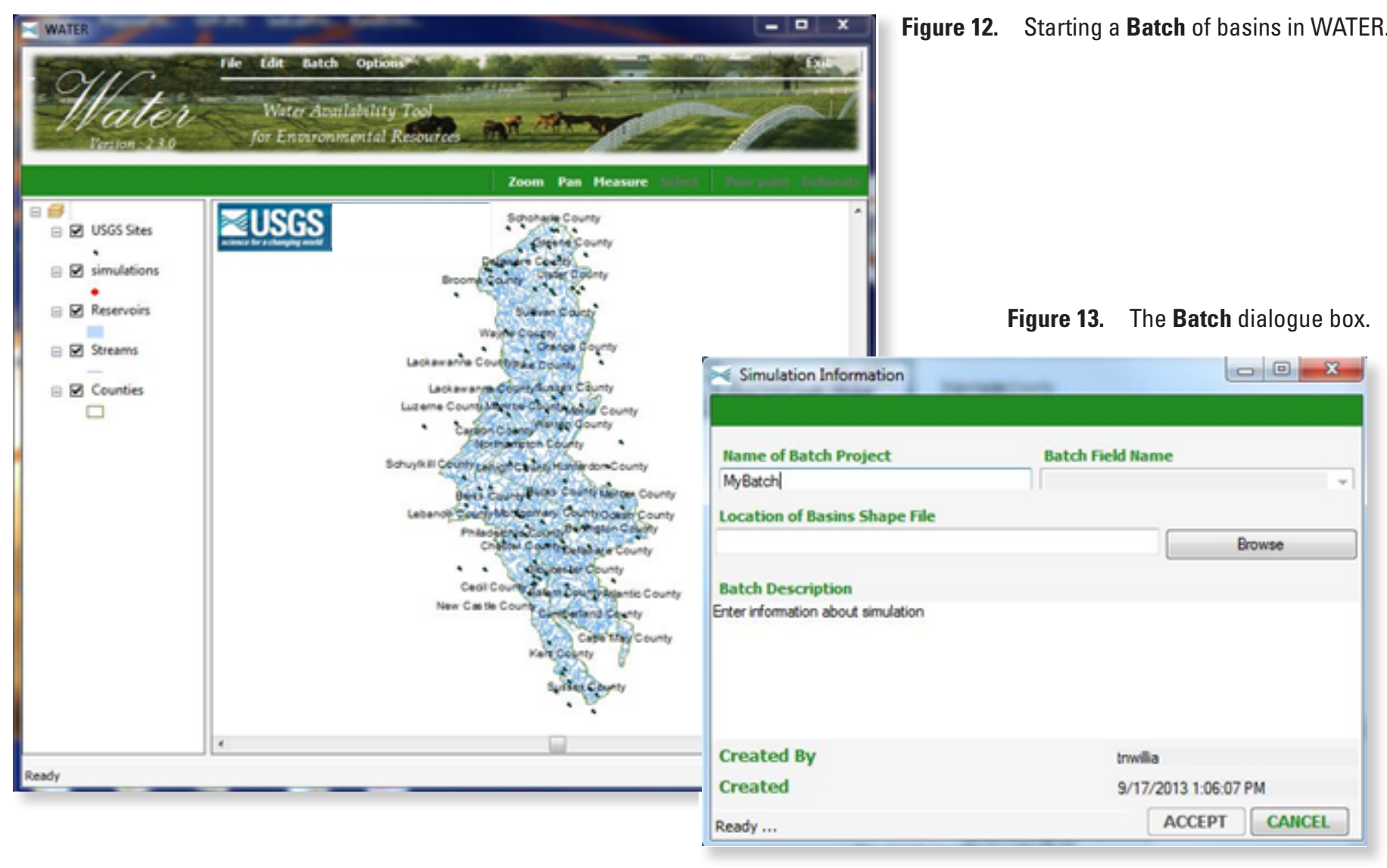

This process will run each basin individually — it does not matter if the basins are nested. Depending on how many basins you have, this process could take several hours. 


\section{Areal Limitations}

WATER was developed for basins characterized by areas of less than $2,000 \mathrm{~km}^{2}$; this coincides with the largest, unregulated basins in the DRB. Simulation of daily streamflow will be less accurate for basins larger than $2,000 \mathrm{~km}^{2}$ because there is no routing to account for delayed streamflow in large basins. WATER will not simulate streamflow for basins that are larger than $17,000 \mathrm{~km}^{2}$ in areal extent because of memory limitations.

\section{Time Period Included in Simulations}

The database provided with WATER includes a climatic record that extends from January 1, 1980, through December 31, 2011. The first year will not be included in the simulation output, providing a year for the model to equilibrate or "spin up"; this provides 11,322 days. Scenario testing that involves GCMs (discussed below in Section 3 of this report) uses the same climatic record altered by GCM- and RCP-specific change factors, enabling comparison between historical and forecasted time periods.

\section{General Circulation Model Simulations}

After using the waterapputils (discussed in Section 3 of this report) to generate "changed" simulations that incorporate general circulation model (GCM) change factors, individual basins must be run separately - even if they were originally processed as part of a batch. If the potential evapotranspiration (PET) change-factor approach is to be incorporated (as is recommended):

1. Open WATER.

2. Select File $->$ Open.

3. Navigate to the location of a GCM simulation. This will be nested inside a folder that is nested in the original basin folder. For example: USGS/water/simulations/BatchName/BasinID/waterapputils-gcmdelta_NCAR_RCP85_2060/WATERSimulation (this is an XML document).

4. Open this file and allow it to load.

5. Click Run, as in the individual basin approach.

This process can take several hours depending on the size of the basin, because it is replacing the original Hamon-based daily PET with that calculated using the radiation-based change factor $\left(\delta_{\text {PETpFF }}\right.$ discussed in Williamson and others, 2015).

In some cases, forecasted streamflow can be estimated without using the changed PET; however, this usually will lead to an overestimate of PET. To do this, move or rename the pet-timeseries file. This simulation will run faster, similar to a historical simulation.

\section{Land-Cover Projections}

Land-cover layers for 2030 and 2060, analogous to the NLCD produced by the Multi-Resolution Land Characteristics Consortium, are included in the "anth" (anthropogenic) folder. These forecasted layers use the same land-cover classification as the 2011 version used for historical simulations. It is best to keep a labeled copy of all three time periods - 2011, 2030, and 2060. To use one of these forecasts, the "mrlc" raster must be replaced with the desired snapshot by deleting the current "mrlc," creating a copy of land cover for the desired time period, and renaming this copy as "mrlc"; you also can use your metadata to differentiate these rasters. WATER only will use the version referred to as "mrlc." 


\section{Section 3. Instruction Manual for WATER Application Utilities-waterapputils version 1.0 .0}

\section{Description}

waterapputils is a tool used for analyzing, processing, and updating model simulations from the Water Availability Tool for Environmental Resources (WATER) decision support system (DSS) of the U.S. Geological Survey Indiana and Kentucky Water Science Center. The waterapputils tool is written in Python ${ }^{\mathrm{TM}}$ (https://www.python.org/), and adds new functionality, outside the WATER DSS, by allowing users to apply various management scenarios using:

- A change-factor (delta or $\delta$ ) approach with data from the Coupled Model Intercomparison Project (CMIP5), and

- Aggregated water-use data to evaluate potential scenarios of water availability.

waterapputils has a Command Line Interface and a Graphical User Interface along with batch scripts, including Run Sample Datasets Shell Script and Process Many Simulations Shell Script, to help automate processing tasks and run unit tests.

The WATER DSS is a graphical user interface (GUI), written in VB.NET, wrapped around a variant of the semi-distributed rainfall-runoff model referred to as TOPMODEL (TOPography based hydrological MODEL) developed by Keith Beven, Professor at Lancaster University. TOPMODEL estimates river discharge and spatial soil-water deficit patterns for a particular catchment basin using topographic, climatic, and pedologic input-data parameters. WATER combines TOPMODEL with an estimation of runoff from impervious surfaces derived by using the curve number approach described in U.S. Department of Agriculture (USDA) Technical Release 55 (TR-55; USDA, 1986) to evaluate runoff generated from impervious areas. The original WATER DSS was developed by the U.S. Geological Survey. Additional references for the WATER DSS include Williamson and others (2009, 2013).

Some sample highlights of waterapputils include:

- Processes WATER simulation output files (txt format).

- Processes WATER simulation database files that store information about a particular model simulation (xml format).

- Applies various general circulation models (GCMs; table 2) to model simulations for a particular basin or set of basins based on the spatial intersection of the watershed(s) of interest with the GCM scenario coverage of interest. Four CMIP5 models are included, with two representative concentration pathway (RCP) scenarios each (RCPs 4.5 and 8.5; table 3); data represent 25-year normals (means) centered on 2030 and 2060.

- Applies water-use data to model simulations for a particular watershed or set of watersheds based on the spatial intersection of the watershed(s) of interest with the water-use coverage.

- Generates plots of all parameters in WATER output files (txt format) with simple statistics.

- Generates plots of time series parameters in WATER-simulation database files (xml format) (fig. 14).

- Generates comparison and difference plots between two WATER-simulation output files.

- Generates comparison and difference plots between two WATER-simulation database files.

- Generates maps of the study area for a particular model simulation using basemap (http://matplotlib.org/basemap/), a python library for plotting two-dimensional data.

- Logs errors and tracebacks.

- Provides a multithreaded GUI referred to as waterapputils_gui, allowing the user to execute tools in the background without the software becoming unresponsive. 


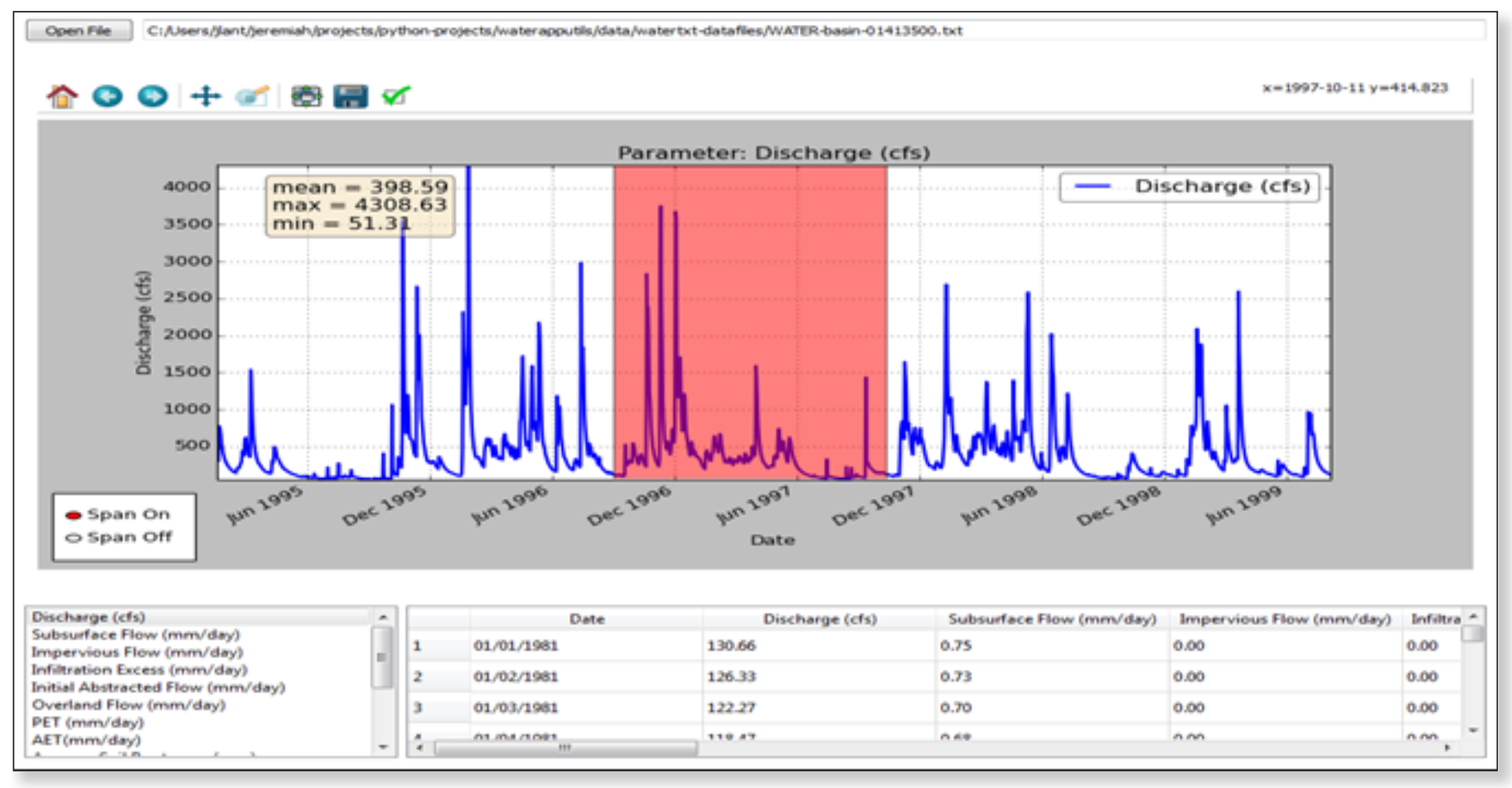

Figure 14. Sample hydrograph produced after processing and analyzing WATER output files using the graphical user interface.

\section{Documentation}

Documentation of the code, guides detailing the processes involved in applying water use and the GCM deltas, additional information about waterapputils, and a gallery of output images are available at $\mathrm{http} / / \mathrm{jlant-usgs.github.io/waterapputils/docs/html/}$ index.html.

Additionally, the documentation pages can be viewed by navigating to the docs/_build/html directory included with waterapputils and opening the index.html file in a Web browser $\left(\right.$ Chrome $^{\mathrm{TM}}$, Firefox $^{\circledR}$, Internet Explorer ${ }^{\circledR}$, etc.).

\section{Tutorials}

A series of video tutorials were made that describe and detail how to use waterapputils with many of the example sample data sets.

The following are the tutorial topics covered:

1. General Overview (48 minutes),

2. Command Line Interface (73 minutes),

3. Graphical User Interface (46 minutes).

Download the waterapputils video tutorials at $\mathrm{ftp} / / / \mathrm{ftpext}$.usgs.gov/pub/er/ky/louisville/jglant/waterapputils/waterapputils-video-tutorials.zip. 


\section{Software Requirements}

The waterapputils software can be launched from the waterapputils folder after the python libraries necessary to run waterapputils are installed in the suggested/default location for your system. A full installation of one of the Python distributions that follow is recommended for the dependencies to match the Python 2.7 download. This full installation is available using the dropdown menu - it may not be the default option. Otherwise, some of these dependencies will not be installed or will not install the required version. The pythonxy and Basemap downloads are provided here: ftp://ftpext.usgs.gov/pub/er/ky/louisville/jglant/ waterapputils/waterapputils-pythonxy2.7.6.1-downloads.zip.

It is recommended that this combination be used to avoid any complications. However, in some cases, alternative approaches might be necessary:

- pythonxy-This program is recommended because of how it interacts with the Microsoft Windows ${ }^{\circledR}$ operating system. (A full installation, which is not the default option, is required).

- Anaconda $^{\circledR}$

- Enthought

The following is a list of dependencies required by the program. Instead of installing these dependencies independently, it is strongly recommended that users install one of the scientific Python distributions noted earlier in this section that will come bundled with most of these dependencies (excluding Basemap):

- Python $==2.7$. $^{*}$ This is the version of Python required to run the program.

- $\operatorname{NumPy}>=1.8 .0$

- matplotlib $>=1.3 .1$

- nose $>=1.3 .0$

- GDAL $>=1.11 .0$

- PyQt4 > = 4.9.6

- Basemap $>=1.0 .2$ - This dependency must be installed separately even when using a full installation.

The PythonXY 2.7.6.1 version, which includes all the requirements listed above, and the Basemap 1.0.2 plugin can be downloaded from: ftp://ftpext.usgs.gov/pub/er/ky/louisville/jglant/waterapputils/waterapputils-pythonxy2.7.6.1-downloads.zip.

\section{Downloading and Installing the Program}

waterapputils is available at the top of the waterapputils page: http://jlant-usgs.github.io/waterapputils/. The program can be downloaded as a ZIP file, which can be copied and extracted anywhere on your system.

This site also includes a link to view additional information about the program on GitHub. 


\section{Running waterapputils}

Navigate to the |waterapputils-master|waterapputils-master|waterapputils folder that you extracted.

Select the wateapputils_gui python (PY) file and "right-click" to select "Open with python." Please be patient, as this could take as many as 5 minutes to launch depending on your system and what else is running. You now can apply water use, process .xml files for GCM scenarios, and compare simulations using the GUI (fig. 15).

If, instead, you prefer to use the command line, an explanation of individual commands is available here and at the GitHub site.

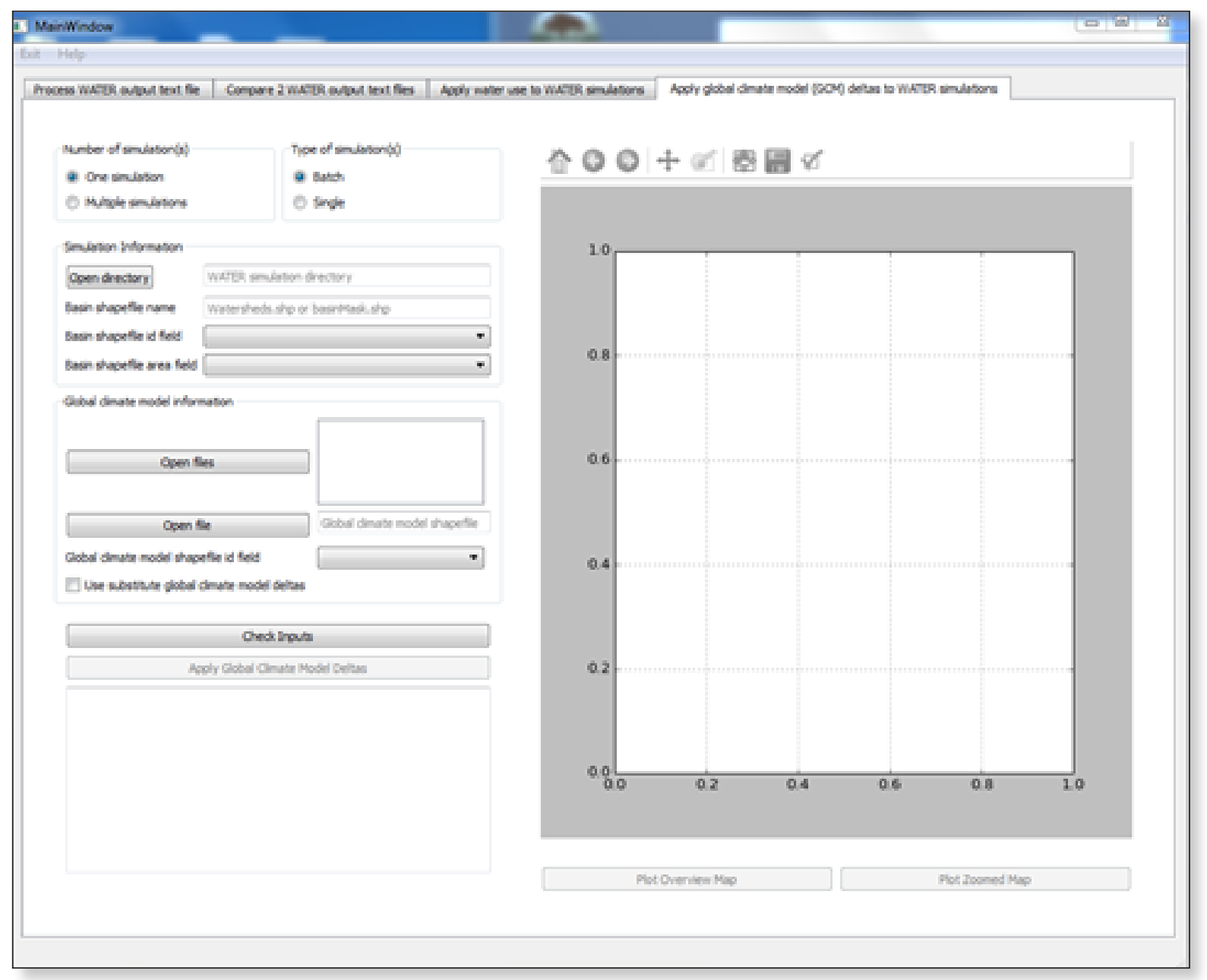

Figure 15. The waterapputils graphical user interface.

\section{Editing Settings in user_settings.py}

All settings for running waterapputils are contained in the user_settings.py file. A user can edit the settings by editing the Python string variables. Most variables are path variables to required data files and basin shapefile attribute variables. A user typically will only edit the section referred to as WATER simulation information. This section contains information about a WATER simulation. A WATER simulation can be either a single simulation or a batch simulation. Each simulation type has a few different outputs along with a different directory structure.

A single simulation corresponds to basins that were delineated within the WATER DSS using a pour point. A batch simulation corresponds to basins that were pre-delineated and were run within the WATER DSS. 


\section{Command Line Interface}

This program must be executed from the waterapputils directory.

\section{Usage:}

\$ python waterapputils.py [option]

\section{Command Line Arguments:}

\begin{tabular}{|c|c|}
\hline Commands & Description \\
\hline$-\mathrm{h}$ & Show list of available commands \\
\hline -watertxt & List WATER simulation output file(s) to process; WATER. txt \\
\hline -watertxtfd & Open file dialog window to select WATER simulation output file(s) to process; WATER. $t x t$ \\
\hline -watertxtcmp & List two WATER simulation output file(s) to compare; WATER. txt \\
\hline -watertxtcmpfd & Open file dialog window to select two WATER simulation output file(s) to compare; WATER . txt \\
\hline -waterxml & List WATER simulation database file(s) to process; WATERSimulation.xml \\
\hline -waterxmlfd & $\begin{array}{l}\text { Open file dialog window to select WATER simulation database file(s) to process; WATERSimu- } \\
\text { lation. xml }\end{array}$ \\
\hline -waterxmlcmp & List two WATER simulation database file(s) to compare; WATERSimulation. xml \\
\hline -waterxmlcmpfd & $\begin{array}{l}\text { Open file dialog window to select two WATER simulation database files to compare; WATER- } \\
\text { Simulation.xml }\end{array}$ \\
\hline -applygcmdeltas & $\begin{array}{l}\text { Apply GCM deltas to WATER-simulation file(s); WATERSimulation.xml; details specified in } \\
\text { user_settings.py }\end{array}$ \\
\hline $\begin{array}{l}\text { - applysubgcmdeltas } \\
\text { applysubgcmdeltas }\end{array}$ & $\begin{array}{l}\text { Apply updated GCM deltas from sub_gcm_delta_info_file_name variable in user_set- } \\
\text { tings.py to WATER-simulation file(s); WATERSimulation.xml; details specified in } \\
\text { user_settings.py }\end{array}$ \\
\hline -applywateruse & $\begin{array}{l}\text { Apply water-use data to WATER-simulation output file(s); WATER.txt; details specified in } \\
\text { user_settings.py }\end{array}$ \\
\hline -applysubwateruse & $\begin{array}{l}\text { Apply water-use data from sub_wateruse_info_file_name variable in user_settings.py } \\
\text { to WATER-simulation output file(s); NOTE: this is necessary if no water-use points are inter- } \\
\text { sected by a basin_-the file has been written to default to zero water use; WATER .txt; details } \\
\text { specified in user_settings.py }\end{array}$ \\
\hline -oasis & $\begin{array}{l}\text { List WATER-simulation output file(s) to process; creates output data file(s) for Delaware River } \\
\text { Basin Commission's DRB-Planning Support Tool program-a tab delimited file(s) of timeseries } \\
\text { of discharge. NOTE: WATER-simulation output file must have the Discharge + Water Use } \\
\text { column. If no water use is preferred, water use should be applied using a factor of zero }\end{array}$ \\
\hline -ecoflowstationid & $\begin{array}{l}\text { List WATER-simulation output file(s) to process; creates output data file(s) for EflowStats R pro- } \\
\text { gram (Thompson and Archfield, 2014) — a comma separated file(s) of timeseries of discharge } \\
\text { for a specific basin (station) id }\end{array}$ \\
\hline -ecoflowdaxml & $\begin{array}{l}\text { List WATER-simulation database } \mathrm{xml} \text { file(s) to process; creates output data file(s) for EflowStats } \\
\mathrm{R} \text { program-a comma separated file(s) of basin (station) id and its respective drainage area in } \\
\text { square miles calculated using data in the WATERSimulation. } \mathrm{xml}\end{array}$ \\
\hline -ecoflowdashp & $\begin{array}{l}\text { List basin or watershed shapefile(s) to process; creates output data file(s) for EflowStats R } \\
\text { program—a comma separated file(s) of basin (station) id and its respective drainage area in } \\
\text { square miles calculated from the shapefile(s) }\end{array}$ \\
\hline
\end{tabular}


Command Line Arguments:-Continued

\begin{tabular}{|c|c|}
\hline Commands & Description \\
\hline -outfilename & $\begin{array}{l}\text { OPTIONAL : output filename to be used with -ecoflowdaxml or -ecoflowdashp } \\
\text { commands in writing the drainage area comma separated file }\end{array}$ \\
\hline -labelfield & $\begin{array}{l}\text { OPTIONAL : label field name (basin number / station id) to be used with -ecoflowdashp com- } \\
\text { mand in writing the drainage area comma separated file; default label field is the FID in the } \\
\text { basin(s) shapefile }\end{array}$ \\
\hline - areafield & $\begin{array}{l}\text { OPTIONAL : area field name in a basin(s) shapefile to be used with -ecoflowdashp } \\
\text { command in writing the drainage area comma separated file; default action is to calculate area } \\
\text { from the shapefile(s) }\end{array}$ \\
\hline -samplesingle & $\begin{array}{l}\text { OPTIONAL : flag used with -applywateruse, -applysubwateruse, -applygcmdeltas, } \\
\text {-applysubgcmdeltas to specify the use of the sample single simulation datasets }\end{array}$ \\
\hline -samplebatch & $\begin{array}{l}\text { OPTIONAL : flag used with - applywateruse, -applysubwateruse, -applygcmdeltas, } \\
\text {-applysubgcmdeltas to specify the use of the sample batch simulation datasets }\end{array}$ \\
\hline -simdir & $\begin{array}{l}\text { OPTIONAL : flag used with - applywateruse, -applysubwateruse, -applygcmdeltas, } \\
\text {-applysubgcmdeltas to specify a path to a specific WATER simulation instead of specify- } \\
\text { ing it in user_settings.py }\end{array}$ \\
\hline
\end{tabular}

Example-processing a WATER.txt file:

\$ python waterapputils.py -watertxt <path-to-WATER.txt-file>

Example_-running water use using the settings in user_settings.py:

\$ python waterapputils.py -applywateruse

Example-running water use by supplying a path to a simulations directory instead of specifying the simulations directory in user_settings.py:

$\$$ python waterapputils.py -applywateruse -simdir <path-to-simulations-directory> 


\section{Run Sample Datasets Shell Script with run_sample_datasets.sh}

The shell script run_sample_datasets.sh is a shell script that can be used to run automated tests and run many of the command line arguments using the sample datasets provided with waterapputils.

\section{Usage—shell script to test waterapputils:}

\$ run_sample_datasets.sh [option]

\$run_sample_datasets.sh [[ [-txt] [-xml] [-wateruse] [-oasis] [-ecoflowstationid] [ecoflowdaxml] [-ecoflowdashp] [-gcmdelta] [-mapsim] [-all] [-tests ]-makeclean] | $[-\mathrm{h}]]$

Command Line Arguments for the Shell Script run_sample_datasets.sh:

\begin{tabular}{|c|c|}
\hline Commands & Description \\
\hline$-\mathrm{h}$ & Show list of available commands \\
\hline$-t x t$ & $\begin{array}{l}\text { Run -watertxt and -watertxtcmp using the sample WATER simulation output TEXT files } \\
\text { (WATER.txt) }\end{array}$ \\
\hline$-\mathrm{xml}$ & $\begin{array}{l}\text { Run -waterxml and -waterxmlcmp using the sample WATER simulation output XML files } \\
\text { (WATERSimulation. } x m 1 \text { ) }\end{array}$ \\
\hline -wateruse & Run and apply water-use data to sample WATER simulations; single and batch simulations \\
\hline -subwateruse & $\begin{array}{l}\text { Run and apply substitute water-use data to sample WATER simulations; single and batch } \\
\text { simulations }\end{array}$ \\
\hline -gcmdelta & $\begin{array}{l}\text { Run and apply general circulation model data to sample WATER simulations; single and batch } \\
\text { simulations }\end{array}$ \\
\hline - subgcmdelta & $\begin{array}{l}\text { Run and apply substitute water-use data to sample WATER simulations; single and batch simu- } \\
\text { lations }\end{array}$ \\
\hline -oasis & $\begin{array}{l}\text { Create a Delaware River Basin Commission's DRB-Planning Support Tool formatted water- } \\
\text { use output file using the sample water use applied WATER TEXT file }\end{array}$ \\
\hline -ecoflowstationid & $\begin{array}{l}\text { Create an EflowStats formatted water-use output file using the sample water use applied } \\
\text { WATER TEXT file }\end{array}$ \\
\hline - ecoflowdaxml & $\begin{array}{l}\text { Create an EflowStats formatted drainage area output file using the sample WATER XML file to } \\
\text { calculate basin area }\end{array}$ \\
\hline -ecoflowdashp & Create an EflowStats formatted drainage area output file using the sample basin shapefiles \\
\hline -mapsim & Create maps for single and batch simulations \\
\hline$-a l l$ & $\begin{array}{l}\text { Run series of commands, including -tests, -txt, -xml, -wateruse, -gcmdelta, } \\
\text {-oasis, -ecoflowstationid, -ecoflowdaxml, -ecoflowdashp, mapsim }\end{array}$ \\
\hline -tests & Run units tests; use nosetests \\
\hline -makeclean & $\begin{array}{l}\text { Cleans/removes all output of running sample dataset in in the sample-water-simulations } \\
\text { directory }\end{array}$ \\
\hline
\end{tabular}

\section{Example-apply water use to delineated and batch simulations:}

\$ run_sample_datasets.sh -wateruse 


\section{Applying Water Use or General Circulation Model Change Factors to Many WATER Simulations Using run_simulations.sh}

The shell script run_simulations.sh is a shell script that can be used to automate the processing of many WATER simulations. run_simulations.sh can be used to apply water use or general circulation model (CGM) change scenarios to multiple WATER simulations that are contained in the same directory. A user will provide a valid option along with the path to the directory containing all WATER simulations that need to be processed. This directory should contain all the same type of WATER simulations: delineated (that is, delineated within WATER GUI from a pour point) or batch, but not both. A user should ensure that the proper settings for processing a delineated or batch simulation are set in the user_settings.py file. Note that the simulation_directory variable will be ignored when using this script, but all other settings will be used accordingly.

Usage-shell script for applying water use or GCM deltas to WATER simulations:

\$ run_simulations.sh [option] <path-to-simulations-directory>

\$ run_simulations.sh [[ [-applywateruse] [-applysubwateruse] [-applygcmdelta]

[-applysubgcmdelta] ] 〈path-to-simulations-directory> | [-h]]

Command Line Arguments for the Shell Script run_simulations.sh:

\begin{tabular}{|c|c|}
\hline Commands & Description \\
\hline$-\mathrm{h}$ & Show list of available commands \\
\hline -applywateruse & Run and apply water-use data to sample WATER simulations; individual and batch simulations \\
\hline -applysubwateruse & $\begin{array}{l}\text { Run and apply substitute water-use data to sample WATER simulations; individual and batch } \\
\text { simulations }\end{array}$ \\
\hline -applygcmdelta & Run and apply GCM deltas to sample WATER simulations; single and batch simulations \\
\hline -applysubgcmdelta & $\begin{array}{l}\text { Run and apply substitute water-use data to sample WATER simulations; individual and batch } \\
\text { simulations }\end{array}$ \\
\hline
\end{tabular}

Example-apply water use to many WATER simulations:

\$ run_simulations.sh -applywateruse <path-to-simulations-directory> 


\section{Graphical User Interface}

The multithreaded GUI, referred to as waterapputils_gui, can be started using the following command or by double-clicking the waterapputils_gui.py file:

\$ python waterapputils_gui.py

The GUI consists of four tabs:

1. Process WATER output text file

2. Compare two WATER output text files

3. Apply water use to WATER simulations

4. Apply GCM deltas to WATER simulations

\section{Process WATER output text file}

A user opens a WATER-simulation output text file (WATER.txt), and all parameters and corresponding data are processed. The first parameter in the data file is plotted initially and the user can use the list on the bottom left of the tab to select different parameters to plot. The plot includes a text area showing some simple statistics for the parameter. All parameters and corresponding data also are placed in a read-only table. A user can interact with the plot using the buttons at the top of the plotting area (zoom, pan, etc.). Additionally, a user can enable a span selector that allows a user to query the data for specific time periods. Upon using the span selector, the simple stats display in the text area with the simple statistics updates for the selected time period.

\section{Compare two WATER output text files}

A user opens two WATER simulation output text files, and the Compare button is enabled. Upon clicking the Compare button, all parameters and corresponding data are processed and compared. The first parameters in the data file are overlaid together with the first file colored as blue and the second file colored as red. A second plot is made, which shows the difference between the respective parameters in each file. The user can use the list at the bottom left of the tab to select different parameters to compare. All parameters and corresponding data for both files are placed in read-only tables. A user can interact with the plots using the buttons at the top of the plotting area (zoom, pan, etc.). Note that the difference plot is tied to the overlay plot, meaning that when a user pans or zooms on the overlay plot, the difference plot will zoom or pan with the overlay plot.

\section{Apply water use to WATER simulations}

This tab allows a user to apply water-use data to WATER simulation output text files (WATER.txt).

Number of simulation(s) - a user selects the number of WATER simulations.

- One simulation (default) — one batch- or individual-type WATER simulation.

- Multiple simulations - more than one batch- or individual-type WATER simulations.

NOTE: The directory containing all WATER simulations to be processed must only contain WATER simulations. Do not include extraneous files or directories in the directory (folder). Additionally, the basin shapefile (Watersheds.shp) must match with the simulations in the folder. 
Type of simulation(s) —a user selects the type of WATER simulation.

- Batch — basins that were pre-delineated and were run within the WATER DSS.

- Delineated -A single basin that was delineated within the WATER DSS.

The following are the directory structures created by WATER for batch and single simulations:

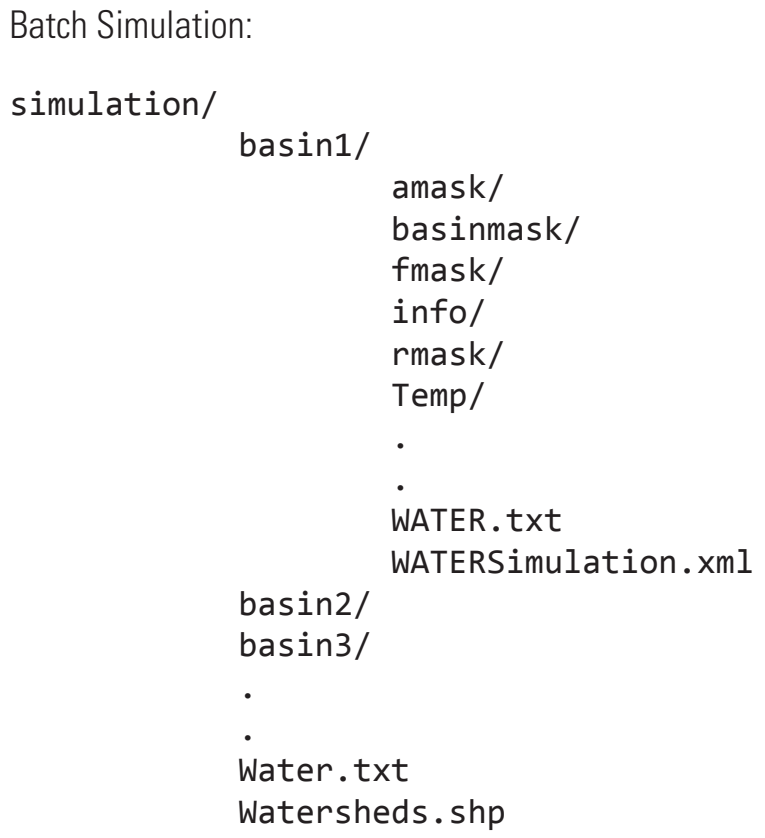

Delineated Simulation:

simulation/

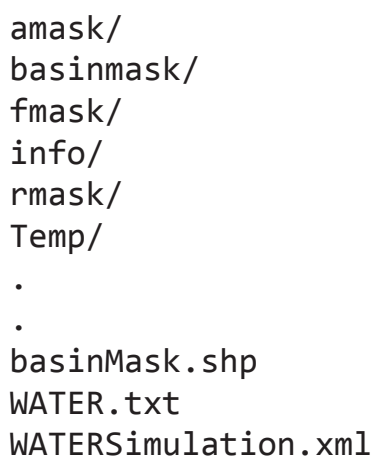

Simulation information - a user selects the WATER simulation of interest for application of water use.

If a valid WATER simulation is selected, the rest of the inputs in the Simulation Information section will auto-populate. A user can select the proper Basin shapefile id field that was used when running the WATER application. The Basin shapefile id field is used by the WATER application to name the output basin directories in the simulation directory structure. The Basin shapefile area field is used to obtain the areas of each respective basin for use in an external ecoflow program.

NOTE: A batch WATER simulation will contain a shapefile of the basins referred to as Watersheds.shp. A delineated WATER simulation will contain a shapefile of the basin referred to as basinMask.shp. A WATER simulation must have an associated Watersheds.shp or basinMask.shp file. 
Water-use information-a user selects the seasonal water-use data files and associated information.

A user selects four seasonal water-use files (provided with WATER database):

1. January, February, March,

2. April, May, June,

3. July, August, September,

4. October, November, December.

A user selects a water-use factor file, which can be used to adjust the water-use data values in the seasonal water-use files.

A user selects the water-use shapefile, which is a shapefile of water-use points across the entire modeling domain.

For the DRB, these files are season_nCPcarb3736_date and dem_basin_centroids.

NOTE: All WATER application shapefiles are in the Albers NAD 83 projection.

A user selects the $i d$ field from the water-use shapefile that corresponds to the $i d$ field used in the water-use data files.

NOTE: The sample water-use files and water-use shapefile have newhydroid as the id field; this also is the case for those provided with the WATER database.

If those basins in the WATER simulation do not overlap/intersect with water-use points, then the user can choose to apply substitute water use (-applysubwateruse) based on that for another basin.

NOTE: To apply substitute water use, the user must first apply water use without this option. The waterapputils program will warn and log any basins in the WATER simulation that do not overlap/intersect with the water-use shapefile points.

The waterapputils program will create a file referred to as wateruse_non_intersecting_centroids.txt in the /waterapputilsinfo/directory with a list of the basins that do not overlap/intersect any water-use points. This file is designed to apply zero water use in those basins that did not intersect any water-use points. A user must manually enter the desired wateruse id (that is, newhydroid) values to be used when applying the substitute water use. To apply substitute water use, the /waterapputils/wateruse_non_intersecting_centroids.txt file must exist and be updated by the user.

A user clicks the Check Inputs button, which checks and ensures that all fields have been entered. After all fields have been entered and the Check Inputs button has been pressed, the Apply Water Use, Plot Overview Map, and Plot Zoomed Map buttons are enabled. If a user clicks the Apply Water Use, then waterapputils applies water use to the WATER simulation using those data provided by the user. The waterapputils_gui will apply water use in a separate thread, meaning that the process will be run in the background, allowing the user to continue using other parts of the waterapputils_gui without interfering with the wateruse processing.

NOTE: When processing water use, a warning about a QPixmap may display. This is not an error, but only a warning that, in this case, can safely be ignored. The warning stems from using the same plotting code used in the command line version of waterapputils when applying water use.

If a user clicks the Plot Overview Map, a map of the WATER basin shapefile (Watersheds.shp or basinMask.shp) is plotted in a zoomed-out view or the entire modeling domain. If a user clicks the Plot Zoomed Map, a map of the WATER basin shapefile (Watersheds.shp or basinMask.shp) is plotted in a zoomed-in view with additional shapefiles (that is, USGS streamgages). 


\section{Apply GCM change factors to WATER simulations}

This tab allows a user to apply GCM deltas to WATER simulation files (WATERSimulation.xml).

Number of simulation(s) —a user selects the number of WATER simulations.

- One simulation (default) —one batch- or delineated-type WATER simulation.

- Multiple simulations - more than one batch- or delineated-type WATER simulations.

NOTE: The directory containing all WATER simulations to be processed must only contain WATER simulations. Do not include extraneous files or directories in the parent directory (folder).

Type of simulation(s) —a user selects the type of WATER simulation.

- Batch-basins that were pre-delineated and were run within the WATER DSS.

- Delineated-A single basin that was delineated within the WATER DSS. The following are the directory structures created by WATER for batch and delineated simulations:

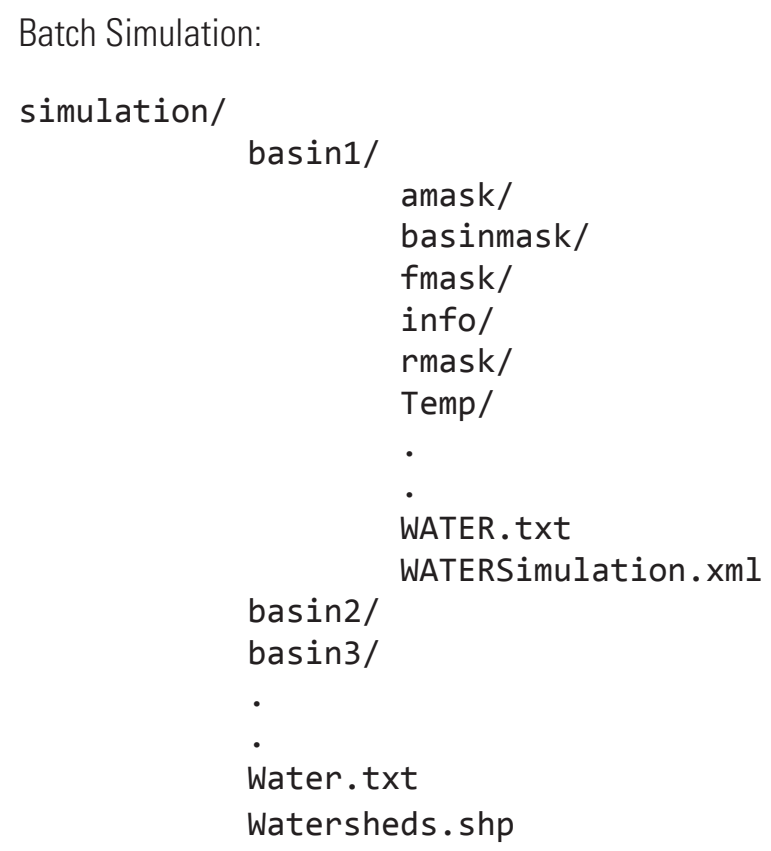

Single Simulation:

simulation/

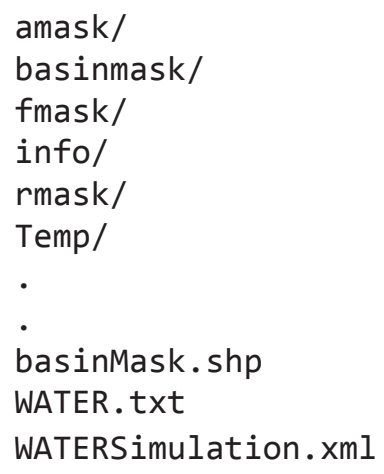


Simulation Information—a user selects the WATER simulation of interest to apply GCM deltas.

If a valid WATER simulation is selected, the rest of the inputs in the Simulation Information section will auto-populate. A user can select the proper Basin shapefile id field that was used when running the WATER application. The Basin shapefile id field is used by the WATER application to name the output basin directories in the simulation directory structure. The Basin shapefile area field is used to obtain the areas of each respective basin.

NOTE: A batch WATER simulation will contain a shapefile of the basins referred to as Watersheds.shp. A delineated WATER simulation will contain a shapefile of the basin referred to as basinMask.shp. A WATER simulation must have an associated Watersheds.shp or basinMask.shp file.

General circulation model change factor information — a user selects three GCM delta files and associated information.

A user selects three GCM delta files from those provided in the GCMdeltas folder of the WATER database:

1. PET.txt,

2. Ppt.txt, and

3. Tmax.txt.

A user selects the GCM shapefile, which is a shapefile of tiles for the corresponding GCM that covers the entire modeling domain.

NOTE: All WATER application shapefiles are in the Albers NAD 83 projection.

A user selects the tile identification field from the GCM shapefile that corresponds to the tile identification field used in the three GCM delta files.

NOTE: The sample GCM delta files and GCM shapefile have Tile as the id field.

If the basins in the WATER use simulation do not overlap/intersect with the GCM shapefile tiles, then the user can choose to apply substitute GCM deltas.

NOTE: To apply substitute GCM deltas, the user must first apply GCM deltas without this option. The waterapputils program will warn and log any basins in the WATER simulation that do not overlap/intersect with the GCM deltas shapefile tiles. The waterapputils program will create a file referred to as gcm_delta_non_intersecting_tiles.txt in a directory referred to as waterapputils-info with a list of the basins that do not overlap/intersect. A user must manually enter the proper GCM delta shapefile id (that is, Tile) values to be used when applying the substitute GCM deltas. To apply substitute GCM deltas, the file referred to as /waterapputils-info/gcm_delta_non_intersecting_tiles.txt must exist.

A user clicks the Check Inputs button, which checks and ensures that all fields have been entered. After all fields have been entered and the Check Inputs button has been pressed, the Apply Water Use, Plot Overview Map, and Plot Zoomed Map buttons are enabled. If a user clicks Apply General Circulation Model Deltas, then waterapputils applies GCM deltas to the WATER simulation given the data provided by the user. The waterapputils_gui will apply GCM deltas in a separate thread, meaning that the process will be run in the background, allowing the user to continue using other parts of the waterapputils_gui without interfering with the GCM delta processing.

NOTE: When processing GCM deltas, a warning about a QPixmap may display. This is not an error, but only a warning that, in this case, can safely be ignored. The warning stems from using the same plotting code used in the command line version of waterapputils when applying GCM deltas.

If a user clicks the Plot Overview Map, a map of the WATER basin shapefile (Watersheds.shp or basinMask.shp) is plotted in a zoomed-out view or the entire modeling domain. If a user clicks the Plot Zoomed Map, a map of the WATER basin shapefile (Watersheds.shp or basinMask.shp) is plotted in a zoomed-in view with additional shapefiles (that is, USGS streamgages). 


\section{Testing}

Automated tests for waterapputils were written using the nose library, and are contained in the tests directory. The nose library must be installed to run tests. Automated tests can be run using the nosetests command at the project level directory (not within the tests directory, but the waterapputils directory containing the tests directory). A successful test run will look something like the following:

$\$$ pwd

/path/to/waterapputils

$\$$ nosetests

SETUP: deltatxt tests

.......TEARDOWN: deltatxt tests

$\ldots$

SETUP: waterxml tests

........TEARDOWN: waterxml tests

Ran 91 tests in $1.049 \mathrm{~s}$

OK

\section{Repository Layout}

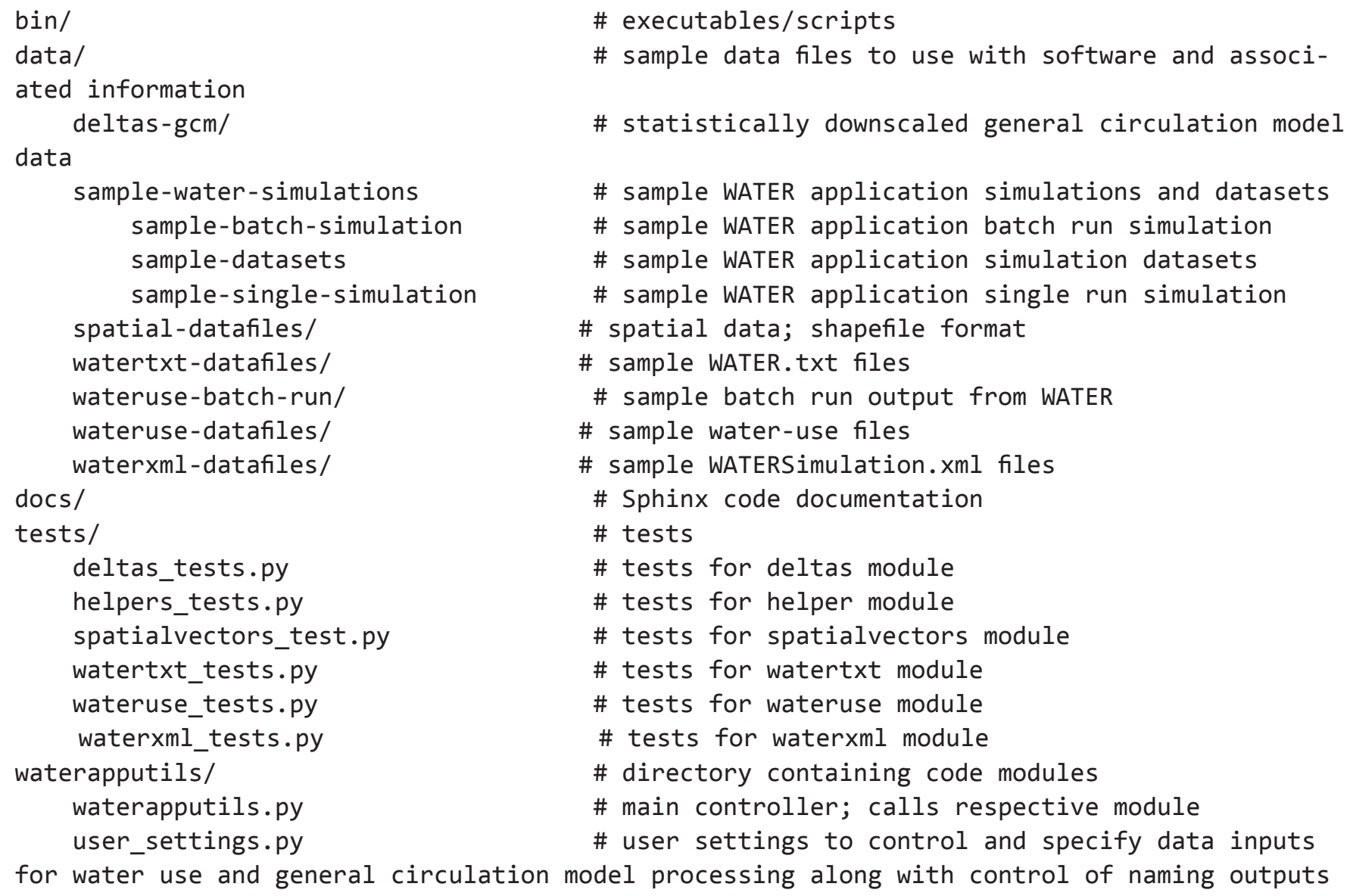


gui/

modules/

deltas.py

deltas_viewer.py

gcm_delta_processing.py

settings from the user_settings.py file

helpers.py

spatialdata_viewer.py

basemap library

spatialvectors.py

specific_output_file_processing.py

OASIS and Eflowstats programs

water_files_processing.py

file processing using settings from the user_settings.py file

waterapputils_logging.py

watertxt.py

files

output files

watertxt_viewer.py

wateruse.py

wateruse_processing.py

from the user_settings.py file

waterxml.py

tion database files

waterxml_viewer.py

simulation database files

Makefile

LICENSE.txt

README.md

requirements.txt

setup.py

ules

run_sample_datasets.sh

ets

run_simulations.sh

to multiple WATER simulations

\# README file
\# gui specific files

\# handles processing of GCM data

\# handles view (plotting) of GCM data

\# handles the GCM delta factors processing using

\# helper functions

\# handles view (mapping) of spatial data; uses

\# handles spatial data

\# handles specific output file processing for external

\# handles the WATER application output and database

\# handles error logging

\# handles processing of WATER.txt simulation output

\# handles view (plotting) of WATER.txt simulation

\# handles processing of water-use data

\# handles the water-use processing using settings

\# handles processing of WATERSimulation.xml simula-

\# handles view (plotting) of WATERSimulation.xml

\# makefile to help clean directories

\# USGS Software User Rights Notice

\# list of requirements/dependencies

\# code for building, distributing, and installing mod-

\# bash script used to run specific or all sample datas-

\# bash script used to apply water use and/or GCM deltas 

